\title{
Assessment of the Molecular Mechanisms of Action of Novel 4-Phenylpyridine-2-One and 6-Phenylpyrimidin-4-One Allosteric Modulators at the $\mathrm{M}_{1}$ Muscarinic Acetylcholine Receptors
}

\author{
Emma T. van der Westhuizen, Arthur Spathis, Elham Khajehali, Manuela Jörg, \\ Shailesh N. Mistry, ${ }^{1}$ Ben Capuano, Andrew B. Tobin, Patrick M. Sexton, \\ Peter J. Scammells, Celine Valant, and Arthur Christopoulos \\ Drug Discovery Biology (E.T.W., A.S., E.K., P.M.S., C.V., A.C.) and Medicinal Chemistry (M.J., S.N.M., B.C., P.J.S.), Monash Institute of \\ Pharmaceutical Sciences, Monash University, Parkville, Victoria, Australia; and Centre for Translational Pharmacology, Institute of \\ Molecular, Cell and Systems Biology, College of Medical, Veterinary and Life Sciences, University of Glasgow, Glasgow, United \\ Kingdom (A.B.T.)
}

Received January 4, 2018; accepted April 18, 2018

\begin{abstract}
Positive allosteric modulators (PAMs) that target the $\mathrm{M}_{1}$ muscarinic acetylcholine $(A C h)$ receptor $\left(M_{1} m A C h R\right)$ are potential treatments for cognitive deficits in conditions such as Alzheimer disease and schizophrenia. We recently reported novel 4-phenylpyridine-2-one and 6-phenylpyrimidin-4-one $\mathrm{M}_{1} \mathrm{mAChR}$ PAMs with the potential to display different modes of positive allosteric modulation and/or agonism but whose molecular mechanisms of action remain undetermined. The current study compared the pharmacology of three such novel PAMs with the prototypical first-generation PAM, benzyl quinolone carboxylic acid (BQCA), in a recombinant Chinese hamster ovary $(\mathrm{CHO})$ cell line stably expressing the human $M_{1} m A C h R$. Interactions between the orthosteric agonists and the novel PAMs or BQCA suggested their allosteric effects were solely governed by modulation of agonist affinity. The greatest degree of positive
\end{abstract}

co-operativity was observed with higher efficacy agonists, whereas minimal potentiation was observed when the modulators were tested against the lower efficacy agonist, xanomeline. Each PAM was investigated for its effects on the endogenous agonist ACh on three different signaling pathways [extracellular signalregulated kinases 1/2 phosphorylation, inositol monophosphate $\left(\mathbb{P}_{1}\right)$ accumulation, and $\beta$-arrestin-2 recruitment], revealing that the allosteric potentiation generally tracked with the efficiency of stimulus-response coupling, and that there was little pathway bias in the allosteric effects. Thus, despite the identification of novel allosteric scaffolds targeting the $M_{1} m A C h R$, the molecular mechanism of action of these compounds is largely consistent with a model of allostery previously described for BQCA, suggesting that this may be a more generalized mechanism for $M_{1}$ mAChR PAM effects than previously appreciated.

\section{Introduction}

The muscarinic acetylcholine $(\mathrm{ACh})$ receptors $(\mathrm{mAChRs})$ belong to the rhodopsin-like (class A) family of G protein-

This work was supported by National Health and Medical Research Council Program Grant [APP1055134]. A.C. is a senior principal and P.M.S. a principal research fellow of the National Health and Medical Research Council of Australia. C.V. is supported by a Future Fellowship from the Australian Research Council. E.T.v.d.W. is supported by an Early Career Fellowship from the National Health and Medical Research Council of Australia.

This work has been presented in part at the Australasian Society of Clinical and Experimental Pharmacologists and Toxicologists (ASCEPT) and the Molecular Pharmacology of GPCRs (MPGPCR) joint scientific meeting, 27-30 Nov., 2016, Melbourne, Australia, and at the GPCR Workshop 2017, 5-9 Dec., Kona, Hawaii.

${ }^{1}$ Current affiliation: Centre for Biomolecular Sciences, University of Nottingham, University Park, Nottingham, United Kingdom.

https://doi.org/10.1124/mol.118.111633. coupled receptors (GPCRs). Five existing, distinct mAChR subtypes (denoted $\mathrm{M}_{1}-\mathrm{M}_{5}$ ) exhibit a widespread distribution throughout the central nervous system and peripheral organs (Caulfield, 1993; Nathanson, 2008; Kruse et al., 2014). The $\mathrm{M}_{1}$, $\mathrm{M}_{3}$, and $\mathrm{M}_{5}$ mAChRs preferentially couple to $\mathrm{G}_{\mathrm{q} / 11}$ proteins, whereas the $M_{2}$ and $M_{4} m A C h R s$ preferentially couple to $G_{i / o}$ proteins. However, an ever-growing array of additional signaling pathways, including those not necessarily mediated by $\mathrm{G}$ proteins, has also been linked to $\mathrm{mAChR}$ activation (Lanzafame et al., 2003).

The $\mathrm{M}_{1} \mathrm{mAChR}$ is highly expressed in the cerebral cortex, hippocampus, striatum, and thalamus (Cortés et al., 1986, 1987; Ehlert and Tran, 1990); regions vital for memory and cognitive and locomotor functions. Therefore, the $\mathrm{M}_{1} \mathrm{mAChR}$

ABBREVIATIONS: ACh, acetylcholine; ANOVA, analysis of variance; BQCA, benzyl quinolone carboxylic acid; CHO, Chinese hamster ovary;

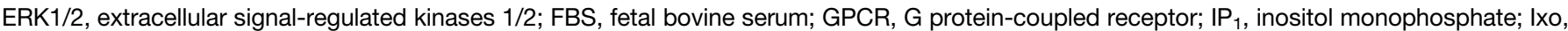
iperoxo; KO, knockout; mAChR, muscarinic acetylcholine receptor; MIPS1674, 4-(2-((4-(1H-pyrazol-4-yl)benzyl)oxy)phenyl)-1-(2hydroxycyclohexyl)pyridin-2(1H)-one; MIPS1745, 1-(2-hydroxycyclohexyl)-4-(2-((6-(1-methyl-1H-pyrazol-4-yl)-pyridin-3-yl)methoxy)phenyl)pyridin2(1H)-one; MIPS1780, 3-(2-hydroxycyclohexyl)-6-(2-((4-(1-methyl-1H-pyrazol-4-yl)- benzyl)oxy)phenyl)pyrimidin-4(3H)-one; MWC, Monod-WymanChangeux; NAL, neutral allosteric ligand; Oxo-M, oxotremorine-M; PAM, positive allosteric modulator; PBZ, phenoxybenzamine; PEI, polyethyleneimine; pERK1/2, phosphorylated ERK1/2; Rluc, Renilla luciferase; Xan, xanomeline; YFP, yellow fluorescent protein. 
has long been implicated in learning and memory, and remains a potential target for the treatment of Alzheimer disease and schizophrenia (Caulfield, 1993; Langmead et al., 2008). A role for the $M_{1} m A C h R$ in treating the cognitive impairment in both of these diseases is further supported by the decrease in $\mathrm{M}_{1} \mathrm{mAChR}$ expression in the prefrontal cortex in brains from schizophrenic patients (Conn et al., 2009; Melancon et al., 2013). Cognition, learning, and memory, which were attenuated in $\mathrm{M}_{1} \mathrm{mAChR}$ knockout (KO) mice, were improved in preclinical studies using the $\mathrm{M}_{1} / \mathrm{M}_{4}$ preferring orthosteric agonist xanomeline (Xan) (Bymaster et al., 2003), whereas memory deficits have been observed upon administration of $\mathrm{mAChR}$ antagonists in $\mathrm{M}_{1} \mathrm{mAChR} \mathrm{KO}$ in mice (Sauerberg et al., 1992; Wess, 2004; Davie et al., 2014). Importantly, Xan demonstrated clinical efficacy, particularly in treating psychosis and cognitive decline in clinical trials of Alzheimer disease and schizophrenia. Despite this, Xan was not pursued further owing to unacceptable off-target effects, attributed largely to a lack of $\mathrm{mAChR}$ subtype selectivity (Bodick et al., 1997; Shekhar et al., 2008).

It is encouraging that mAChRs possess spatially distinct allosteric sites, which can be selectively targeted (Kruse et al., 2013, 2014). Recently, benzyl quinolone carboxylic acid (BQCA) was described as the first highly selective positive allosteric modulator (PAM) of the $\mathrm{M}_{1} \mathrm{mAChR}$, with preclinical efficacy in animal models of cognition (Ma et al., 2009), and has served as a major impetus for new discovery efforts (Kruse et al., 2014). However, significant challenges and unanswered questions remain regarding the optimal type of allosteric ligand for successful progression through preclinical studies to man. For instance, allosteric modulators can display complex behaviors such as "probe dependence," wherein the magnitude and direction of an allosteric effect for the modulator can change depending on which orthosteric ligand is used as a probe for receptor function (Kenakin 2005). Another example is "biased modulation," the ability of different allosteric ligands to engender unique receptor conformations, whereby certain signaling pathways are differentially modulated relative to others (Kenakin and Christopoulos, 2013; Christopoulos, 2014).

The simplest mechanism that explains allostery is the classic Monod-Wyman-Changeux (MWC) model (Monod et al., 1965), which predicts that probe dependence arises as a function of the efficacy of the orthosteric ligand, and that biased modulation cannot occur without the existence of additional active states (Canals et al., 2011; Changeux and Christopoulos, 2016). A characterization of BQCA at the $\mathrm{M}_{1}$ $\mathrm{mAChR}$ revealed that BQCA indeed behaves in a manner generally consistent with a two-state MWC mechanism (Canals et al., 2012; Ehlert and Griffin, 2014). However, this is not always the case with other $\mathrm{mAChR}$ modulators (e.g., Valant et al., 2012), and thus detailed molecular pharmacological characterization is a necessary first step in understanding the mechanism of action of any new allosteric ligands. Although BQCA was a major breakthrough in terms of proof of concept, it possesses a very low affinity for the receptor, as well as additional liabilities that precluded it from further clinical development (Canals et al., 2011; Davoren et al., 2016). Thus, there remains an ongoing need for the discovery of new $\mathrm{M}_{1}$ mAChR PAMs.

Our laboratory recently identified a series of novel $\mathrm{M}_{1} \mathrm{mAChR}$ PAMs with 4-phenylpyridine-2-one and 6-phenylpyrimidin-one scaffolds that are distinct from BQCA (Mistry et al., 2016). However, a detailed mechanistic evaluation of their pharmacological properties has not been undertaken. Thus, the aim of this study was to characterize exemplar molecules from this series of PAMs and compare their behaviors to BQCA, particularly with regards to mechanisms underlying probe dependence and the potential for biased modulation. We found that, despite possessing a chemically distinct scaffold, the novel PAMs generally behave in a manner akin to that of BQCA.

\section{Materials and Methods}

Materials. Dulbecco's modified Eagle's medium and FlpInCHO cells were Invitrogen products (Invitrogen/Thermo Fisher Scientific, Carlsbad, CA). Fetal bovine serum was purchased from Thermo Trace (Melbourne, Victoria, Australia). The IP-One assay kit and reagents were purchased from Cisbio (Codolet, France). $\left[{ }^{3} \mathrm{H}\right] \mathrm{NMS}(70.0 \mathrm{Ci} / \mathrm{m}$ mol) and AlphaScreen protein A IgG beads were purchased from PerkinElmer Life and Analytical Sciences (Waltham, MA). The SureFire cellular extracellular signal-regulated kinases 1/2 (ERK1/2) assay kits were a generous gift from TGR BioSciences (Adelaide, Australia). Polyethyleneimine (PEI, molecular mass, $25 \mathrm{kDa}$ ) was from Polysciences (Warrington, PA). 1-(4-methoxybenzyl)-4-oxo-1,4-dihydroquinoline3 -carboxylic acid (benzyl quinolone carboxylic acid; BQCA), 4-(2-((4-( $1 H$ pyrazol-4-yl)benzyl)oxy)phenyl)-1-(2-hydroxycyclohexyl)pyridin-2( $1 H)$ one (MIPS1674), 1-(2-hydroxycyclohexyl)-4-(2-((6-(1-methyl-1H-pyrazol-4-yl)-pyridin-3-yl)methoxy)phenyl)pyridin-2(1H)-one (MIPS1745), and 3-(2-hydroxycyclohexyl)-6-(2-((4-(1-methyl-1H-pyrazol-4-yl)- benzyl)oxy)phenyl)pyrimidin-4(3H)-one (MIPS1780) were synthesized in house (Mistry et al., 2016). Xanomeline was a generous gift from Dr. Christian Felder (Eli Lilly). Coelenterazine $\mathrm{H}$ was purchased from NanoLight Technologies (Pinetop, AZ). The yellow fluorescent protein (YFP)$\beta$-arrestin-2 construct was a gift from Dr. Marc Caron (Duke University). The $\mathrm{M}_{1}$-Rluc8 constructs were generated in-house as described previously (Yeatman et al., 2014). All other chemicals were purchased from MilliporeSigma (St Louis, MO).

Cell Culture. FlpInCHO cells stably expressing the wild-type human muscarinic acetylcholine $\mathrm{M}_{1}$ receptor $\left(\mathrm{hM}_{1} \mathrm{mAChR} ; 37031 \pm\right.$ 3397 sites/cell) (Mistry et al., 2016) were grown in Dulbecco's modified Eagle's medium [supplemented with $5 \%$ fetal bovine serum (FBS)] and were used for the inositol monophosphate $\left(\mathrm{IP}_{1}\right)$ accumulation and ERK1/2 signaling assays. For the $\beta$-arrestin- 2 recruitment assays, $3 \times$ $10^{6}$ parental FlpInCHO cells were transiently transfected with $0.6 \mu \mathrm{g}$ of $\mathrm{M}_{1}$-Renilla luciferase (Rluc)-8, $1.8 \mu \mathrm{g}$ of YFP- $\beta$-arrestin- 2 , and 3.6 $\mu \mathrm{g}$ of empty pcDNA vector in a $100 \mathrm{~mm}$ dish, using linear polyethyleneimine (PEI/DNA ratio 6:1) diluted in $\mathrm{NaCl}(150 \mathrm{mM})$. DNA/PEI complexes were formed by incubation at room temperature for 15 minutes, then added to the cells and incubated at $37^{\circ} \mathrm{C}$ for 24 hours. Transfected cells were replated into white CulturPlates (PerkinElmer) and incubated for a further 24 hours prior to use in signaling assays.

IP 1 Accumulation Assay. The IP-one assay kit (Cisbio) was used for the quantitative measurement of myo- $\mathrm{IP}_{1}$. Ten thousand cells/well were seeded into 96 -well plates and incubated overnight at $37^{\circ} \mathrm{C}$. The following day, cells were preincubated with $\mathrm{IP}_{1}$ stimulation buffer (10 mM HEPES, $1 \mathrm{mM} \mathrm{CaCl}_{2}, 0.5 \mathrm{mM} \mathrm{MgCl} 2,4.2 \mathrm{mM} \mathrm{KCl}, 146 \mathrm{mM}$ $\mathrm{NaCl}, 5.5 \mathrm{mM}$ D-glucose, $50 \mathrm{mM} \mathrm{LiCl}, \mathrm{pH} 7.4$ ) for 1 hour at $37^{\circ} \mathrm{C}$. Orthosteric and allosteric ligands were added and incubated for a further 1 hour at $37^{\circ} \mathrm{C}$. Cells were lysed in lysis buffer [50 mM HEPES$\mathrm{NaOH}$ pH 7.0, $15 \mathrm{mM} \mathrm{KF}, 1.5 \%$ (v/v) Triton-X-100] and $14 \mu \mathrm{l}$ of cell lysates were transferred into 384-well OptiPlates (PerkinElmer Life Sciences). An $\mathrm{IP}_{1}$ standard curve was prepared and added to the OptiPlates in parallel. Homogenous time-resolved fluorescence resonance energy transfer reagents (cryptate-labeled anti-IP $\mathrm{P}_{1}$ antibody, the $\mathrm{d}_{2}$-labeled $\mathrm{IP}_{1}$ analog; diluted 1:20 in lysis buffer) were added and plates and incubated for 1 hour at $37^{\circ} \mathrm{C}$. Samples were excited at $340 \mathrm{~nm}$ and emission was captured at 590 and $665 \mathrm{~nm}$ using the 
Envision multi-label plate reader (PerkinElmer Life Sciences). $\mathrm{IP}_{1}$ concentrations were interpolated from the standard curve using homogenous time-resolved fluorescence resonance energy transfer ratio values, and responses were normalized to the maximum response elucidated by ACh.

Receptor Alkylation Studies in IP $_{1}$ Accumulation Experiments. Ten thousand cells/well were seeded into poly-D-lysine-coated 96-well plates. Following the initial 1 hour incubation in $\mathrm{IP}_{1}$ stimulation buffer, cells were pretreated for 30 minutes at $37^{\circ} \mathrm{C}$ with varying concentrations of the irreversible orthosteric-site alkylating agent, phenoxybenzamine (PBZ) or vehicle control, followed by three washes with phosphate-buffered saline. The $\mathrm{IP}_{1}$ assay was then performed as described above.

ERK1/2 Phosphorylation. The AlphaScreen-based SureFire kit was used for the quantitative measurement of phosphorylated ERK1/2 (pERK1/2). Twenty-five thousand cells/well were plated into 96 -well plates and incubated overnight at $37^{\circ} \mathrm{C}$. The following day, the growth medium was replaced with serum-free medium for 6 hours at $37^{\circ} \mathrm{C}$, then the cells were stimulated for 5 minutes (peak response from time course, data not shown) with various concentrations of ACh or FBS $(10 \% \mathrm{v} / \mathrm{v})$ with or without different concentrations of allosteric ligands at $37^{\circ} \mathrm{C}$. Cells were lysed in $100 \mu \mathrm{l} /$ well of SureFire lysis buffer at $-20^{\circ} \mathrm{C}$ overnight. Plates were thawed at room temperature and $10 \mu \mathrm{l}$ of the cell lysates were transferred to a 384-well OptiPlates. In reduced lighting conditions, $8.5 \mu \mathrm{l}$ of detection buffer (reaction buffer/activation buffer/acceptor beads/donor beads; 60:10:0.3:0.3) was added and plates were incubated for 1 hour at $37^{\circ} \mathrm{C}$. Fluorescence signal was measured using the Envision multilabel plate reader with AlphaScreen settings. Data were expressed as a percentage of the pERK1/2 mediated by $10 \%$ FBS or maximum $\mathrm{ACh}$ response.

$\boldsymbol{\beta}$-Arrestin-2 Recruitment Assays. FlpInCHO cells were transiently transfected with $\mathrm{M}_{1}$-Rluc8 and YFP- $\beta$-arrestin-2 as described in the cell culture section above. Twenty-four hours later, they were replated into white 96 -well OptiPlates. Cells were equilibrated in Hanks' balanced salt solution for 1 hour at $37^{\circ} \mathrm{C}$. Coelenterazine $\mathrm{H}$ (final concentration $5 \mu \mathrm{M}$ ), was added to each well, then 5 minutes later various concentrations of ligands were added. Luminescence and fluorescence readings were captured 10 minutes after coelenterazine $\mathrm{H}$ addition using the LUMIstar Omega (BMG LabTech, Offenburg, Germany), which allows for the sequential integration of the signals detected at $475 \pm 30$ and $535 \pm 30 \mathrm{~nm}$ using filters with the appropriate band pass. Data are presented as bioluminescence resonance energy transfer (BRET) ratio, calculated as the ratio of YFP to Rluc8 signals and were normalized to the maximum possible BRET ratio elucidated by ACh.

Data Analysis. All data analysis was performed using GraphPad Prism v.7.02 (GraphPad, San Diego, CA). Concentration-response curves were fitted using a three-parameter logistic nonlinear regression model to derive potency $\left(\mathrm{p} E C_{50}\right)$ and efficacy $\left(E_{\max }\right)$ parameters.

$\mathrm{IP}_{1}$ alkylation experiments were globally fitted to an operational model of agonism (Black and Leff, 1983) to determine orthosteric agonist equilibrium dissociation constant (functional affinity; $K_{\mathrm{A}}$ ) and the agonist operational efficacy $(\tau)$, which takes both receptor density and stimulus-response coupling efficiency into account:
A<smiles>COc1ccc(Cn2cc(C(=O)O)c(=O)c3ccccc32)cc1</smiles><smiles>O=c1cc(-c2ccccc2OCc2ccc(-c3cn[nH]c3)cc2)ccn1[C@@H]1CCCC[C@H]1O</smiles>

BQCA<smiles></smiles>

MIPS1674

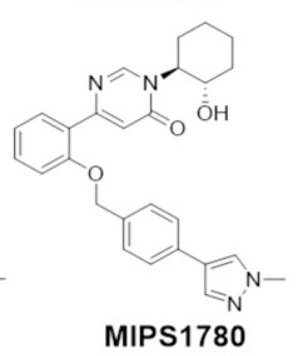

B

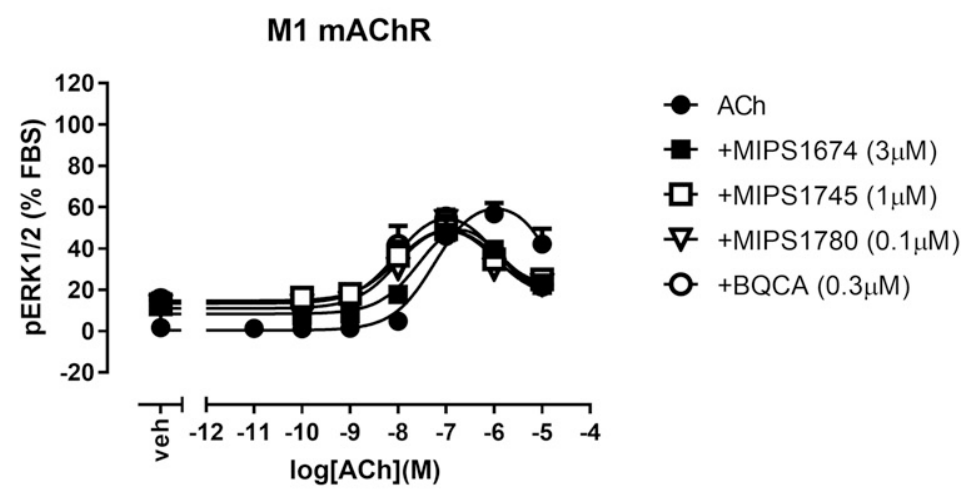

C
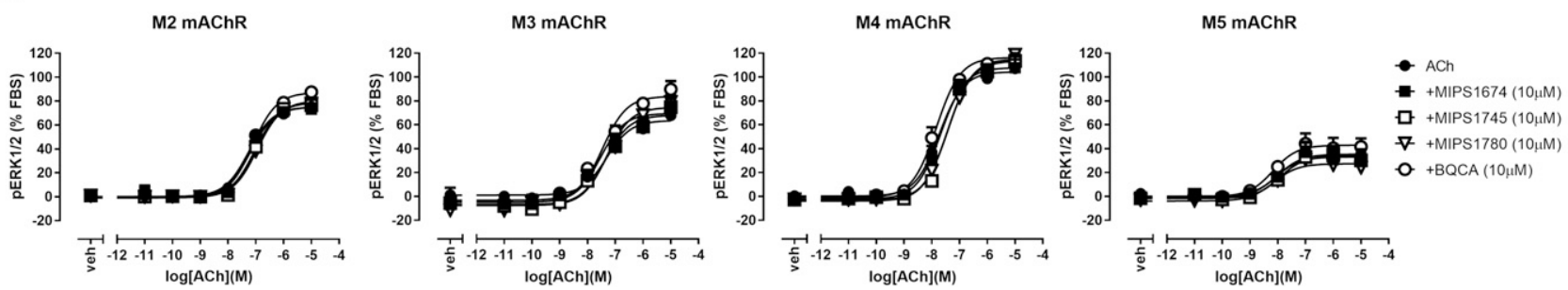

Fig. 1. Novel 4-phenylpyridine-2-ones and 6-phenylpyrimidin-4-one selectively modulate the $\mathrm{M}_{1} \mathrm{mAChR}$ over other mAChR subtypes. (A) The structurally novel $\mathrm{M}_{1}$ mAChR PAMs selected for this study, MIPS1674, MIPS1745 and MIPS1780 (previously published as compounds "14, 17, and 29," respectively, by Mistry et al. (2016)). They were compared with the reference modulator, BQCA. (B) The 4-pheylpyridine-2-ones-and 6-phenylpyrimidin4-one-based analogs all showed intrinsic efficacy and potentiation of the ERK1/2 response at the $\mathrm{M}_{1}$ mAChR. (C) The novel PAMs or BQCA did not modulate ACh-mediated ERK1/2 phosphorylation at the $\mathrm{M}_{2}, \mathrm{M}_{3}, \mathrm{M}_{4}$, or $\mathrm{M}_{5} \mathrm{mAChR}$ subtypes when tested at a concentration of $10 \mu \mathrm{M}$. Data are mean \pm S.E.M. of four independent experiments performed with duplicate repeats. 
TABLE 1

Empirical and operational model parameter estimates for the orthosteric ligands in mediating the $\mathrm{IP}_{1}$ accumulation via activation of the $\mathrm{M}_{1} \mathrm{mAChR}$ in FlpInCHO-hM $\mathrm{H}_{1}$ cells

Concentration-response curves for orthosteric ligands were established in the absence or presence of PBZ pretreatment (followed by extensive washout). Data were fitted using the operational model (eq. 1) to determine the functional affinity $\left(\mathrm{p} K_{\mathrm{A}}\right)$ and operational efficacy $(\log \tau)$ values. Parameter values are the mean \pm S.E.M. of eight independent experiments with repeats in duplicate. Data were analyzed by one-way ANOVA (with $\alpha=0.01$ ) using a Dunnett multiple comparisons test, where $* P<0.05$ was considered to be significantly different to those of the endogenous agonist ACh.

\begin{tabular}{llccrr}
\hline Ligand & $\mathrm{p} E C_{50}{ }^{a}$ & $E_{\max }{ }^{b}$ & $\mathrm{p} K_{\mathrm{A}}{ }^{c}$ & \multicolumn{1}{c}{$\log \tau_{\mathrm{A}}{ }^{d}$} & $\tau_{\mathrm{A}}{ }^{e}$ \\
\hline ACh & $5.79 \pm 0.07$ & $99.7 \pm 2.9$ & $5.26 \pm 0.23$ & $0.55 \pm 0.29$ & 3.6 \\
Ixo & $7.97 \pm 0.09 *$ & $101.3 \pm 3.3$ & $6.99 \pm 0.17^{*}$ & $1.03 \pm 0.23^{*}$ & 10.7 \\
Oxo-M & $6.08 \pm 0.13$ & $90.3 \pm 4.8$ & $5.35 \pm 0.28$ & $0.66 \pm 0.40^{*}$ & 4.6 \\
Xan & $6.96 \pm 0.21^{*}$ & $29.8 \pm 2.7^{*}$ & $6.48 \pm 0.51^{*}$ & $-0.31 \pm 1.3^{*}$ & 0.5 \\
\hline
\end{tabular}

${ }^{a}$ Negative logarithm of the $E C_{50}$ value of the vehicle-pretreated control curve.

${ }^{b}$ Maximal agonist response under the vehicle-pretreated conditions, relative to ACh.

${ }^{c}$ Negative logarithm of the functional affinity value constant $K_{\mathrm{A}}$, derived using eq. 1 .

${ }^{d}$ Logarithm of the operational efficacy parameter for the orthosteric agonist in the absence of PBZ-pretreatment derived using eq. 1 .

${ }^{e}$ Antilogarithm of the operational efficacy parameter.

$$
E=b a s a l+\frac{\left(E_{m}-b a s a l\right) \tau^{n}[A]^{n}}{\tau^{n}[A]^{n}+\left([A]+K_{A}\right)^{n}}
$$

In this model, basal is the response in the presence of vehicle, $E_{\mathrm{m}}$ is the maximum possible pathway response, $[A]$ is the agonist concentration, and $n$ represents the slope of transducer function that links occupancy to response.

Concentration-response curves for the functional interactions between orthosteric and allosteric ligands were globally fitted to the following simplified operational model of allostery and agonism (Aurelio et al., 2009):

$$
E=\text { basal }+\frac{\left(E_{m}-\text { basal }\right)\left([A]\left(K_{B}+\alpha \beta[B]+\tau_{B}[B]\left[E C_{50}\right]\right)^{n}\right.}{\left[E C_{50}\right]^{n}\left(K_{B}+[B]\right)^{n}+\left([A]\left(K_{B}+\alpha \beta[B]\right)+\tau_{B}[B]\left[E C_{50}\right]\right)^{n}}
$$

where basal is the response in the presence of vehicle, $[B]$ is the concentration of allosteric ligand, and $K_{\mathrm{B}}$ represents its equilibrium
A
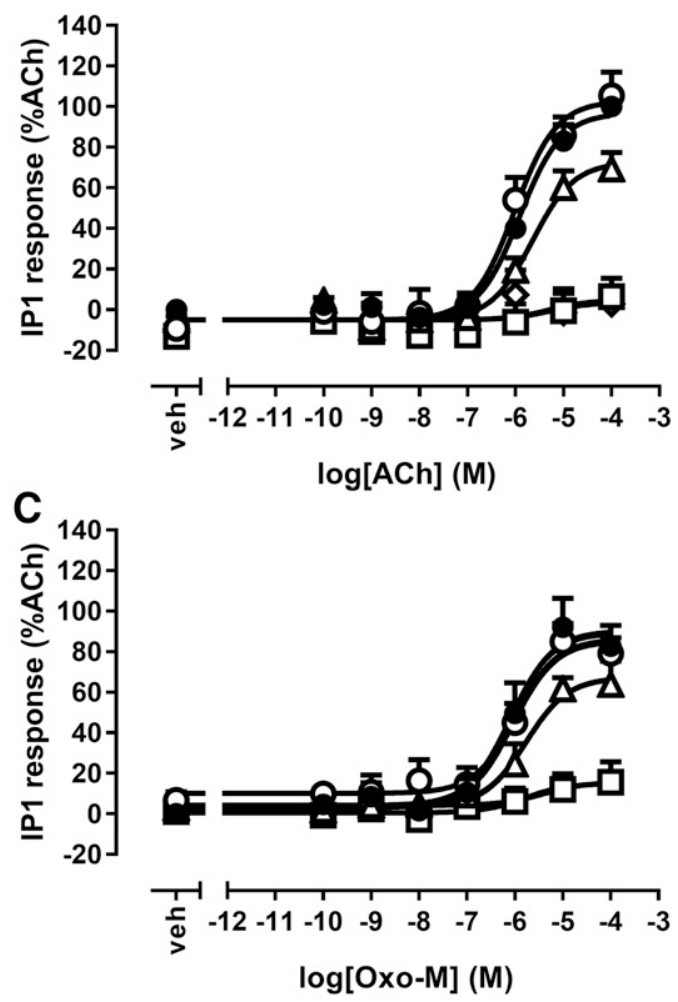

B

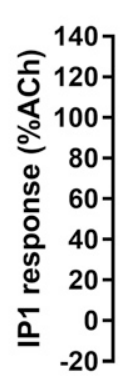

D

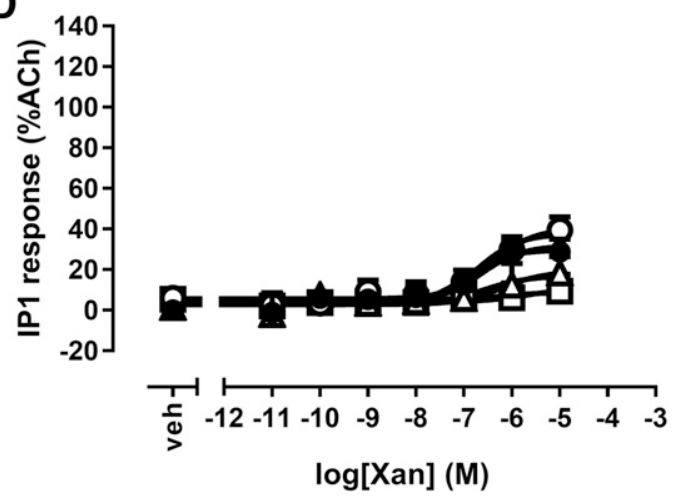

Fig. 2. Receptor alkylation assays identify low receptor reserve in FlpInCHO- $\mathrm{M}_{1}$ cell lines. FlpInCHO- $\mathrm{M}_{1}$ cells were pretreated with different concentrations of phenoxybenzamine (PBZ) for 30 minutes, followed by extensive washout to reduce receptor reserve. Cells were then stimulated for 60 minutes with increasing concentrations of (A) ACh, (B) Ixo, (C) Oxo-M, or (D) Xan. Decreases in $E_{\max }$ and minimal changes in $E C_{50}$ values were observed with all orthosteric ligands, suggesting that the FlpInCHO-M $\mathrm{M}_{1}$ cell line used in this study expressed low levels of $\mathrm{M}_{1} \mathrm{mAChR}_{\mathrm{N}}$. Data are mean \pm S.E.M. of six independent experiments with repeats in duplicate. Fitted curves shown are global analysis on the basis of the operational model (eq. 1). 
dissociation constants. $\tau_{\mathrm{B}}$ represents an operational measure of allosteric ligand efficacy, $\alpha$ denotes the binding cooperativity between orthosteric and allosteric ligand, whereas $\beta$ denotes a scaling factor that quantifies the allosteric effect of the modulator on orthosteric ligand efficacy. This model assumes that all orthosteric ligands are either full agonists at the receptor on both the absence/presence of modulator and/or there is no efficacy modulation (i.e., $\beta=1$ ). As shown in Results, one or both of these assumptions were met with the various orthosteric ligands used, and thus the $\beta$ parameter was constrained to 1. All other parameters are as defined in eq. 1.

Also as shown in Results, the ERK1/2 responses at the $\mathrm{M}_{1} \mathrm{mAChR}$ were bell-shaped. For the purposes of fitting the allosteric operational model to the data, the points defining the decreasing phases of the curves (i.e., those beyond $10 \mu \mathrm{M}$ of agonist) were removed from each curve to allow convergence of the allosteric operational model (eq. 2).

All affinity, potency, and cooperativity values were estimated as logarithms (Christopoulos, 1998), and statistical comparisons between values were by one-way analysis of variance (ANOVA) with either a Neuman-Keuls or Dunnett multiple comparison test. A value of $P<0.05$ was considered statistically significant.

\section{Results}

Novel 4-Phenylpyridine-2-One- and 6-Phenylpyrimidin4-One-Based Compounds are Selective for the $M_{1}$ mAChR over Other mAChR Subtypes. Recent work from our laboratory identified a novel series of 4-phenylpyridine-2one and 6-phenylpyrimidin-4-one $\mathrm{M}_{1}$ mAChR PAMs (Fig. 1A) that represent a different chemical scaffold to BQCA and related analogs (Mistry et al., 2016). When assessed for effects on the $\mathrm{IP}_{1}$ signaling pathway, our preliminary pharmacological characterization indicated that MIPS1674 was an allosteric agonist with minimal PAM activity against ACh, MIPS1745 was a "pure" PAM of ACh with no direct allosteric agonism, whereas MIPS1780 behaved as a mixed PAM-agonist in modulating ACh function (akin to responses observed with BQCA). Thus, the fact that these three PAMs potentially exhibited three different "allosteric phenotypes" (Mistry et al., 2016) formed the basis for selecting them for further pharmacological evaluation. These compounds were initially tested to ensure they were selective for the $\mathrm{M}_{1} \mathrm{mAChR}$ over other mAChR subtypes using an ERK1/2 phosphorylation assay. Figure 1, B and C shows that all PAMs modulated ACh activity at the $\mathrm{M}_{1}$ mAChR, but no modulation of ACh-mediated ERK1/2 responses were observed for $\mathrm{M}_{2}, \mathrm{M}_{3}, \mathrm{M}_{4}$, or $\mathrm{M}_{5} \mathrm{mAChR}$ subtypes with MIPS1674, MIPS1745, MIPS1780, or BQCA (at a concentration higher than that needed to see PAM effects at the $\mathrm{M}_{1} \mathrm{mAChR}$ ), confirming that these modulators were selective for the $\mathrm{M}_{1} \mathrm{mAChR}$. It was also noted that ACh displayed a bell-shaped concentration-response relationship for mediating ERK1/2-phosphorylation at the $\mathrm{M}_{1} \mathrm{mAChR}$, both in the absence or presence of modulator (Fig. 1B). Although the mechanism underlying this effect is
A

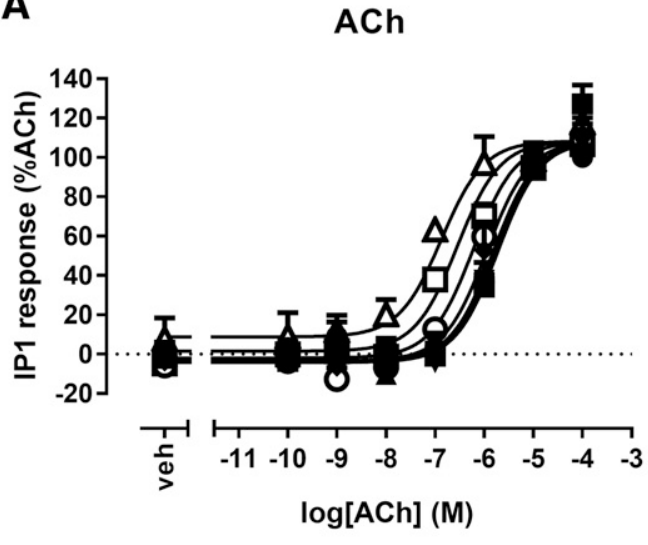

C

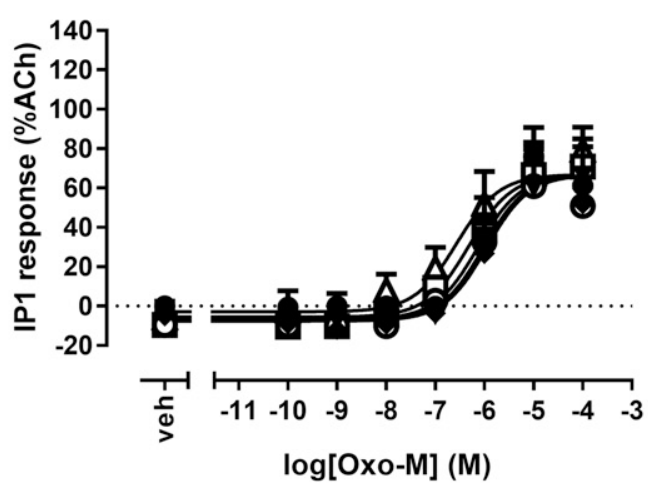

B

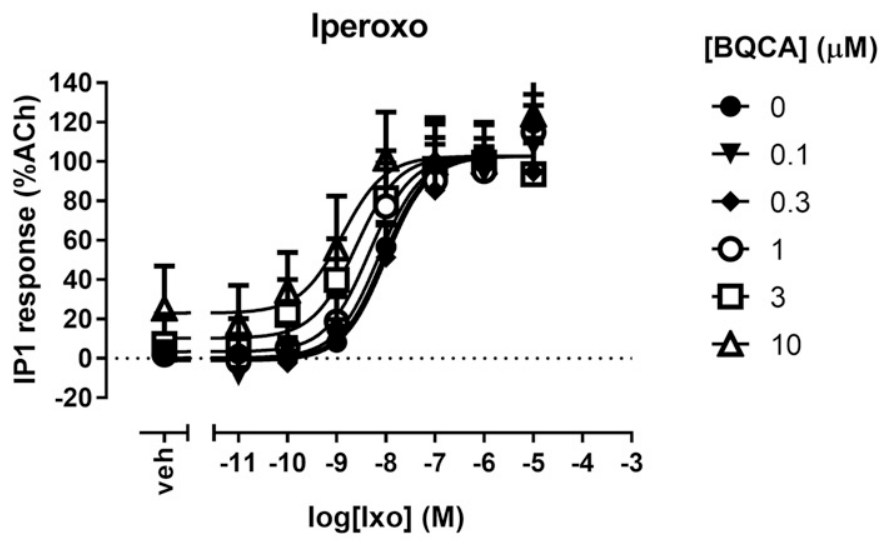

D

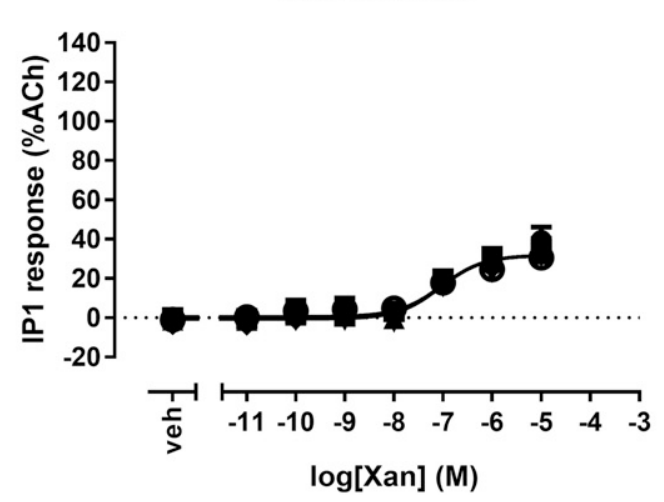

Fig. 3. BQCA displays probe dependence with different agonists in $\mathrm{IP}_{1}$ accumulation. Interaction between (A) ACh, (B) Ixo, (C) Oxo-M, or (D) Xan with or without increasing concentrations of BQCA were performed in FlpInCHO-hM 1 cells at $37^{\circ} \mathrm{C}$ for 1 hour. Data are expressed as a percentage of the maximal ACh response and are the mean \pm S.E.M. of 6-15 independent experiments performed in duplicate. Fitted curves are from global analysis of datasets according to an operational model of allosterism (eq. 2) with parameter estimates shown in Table 2. 
unknown, it is not the result of desensitization or a change in the time-to-peak ACh effect at high concentrations, on the basis of control time-course experiments (not shown).

Determination of $M_{1}$ mAChR Orthosteric Agonist Functional Affinities and Intrinsic Efficacies in Stimulating IP $_{1}$ Accumulation. The next aim of this study was to investigate the potential for probe dependence of the novel allosteric modulators and the contribution of different degrees of intrinsic agonist efficacy to the phenomenon. mAChR agonists of variable efficacies were selected to use as orthosteric probes. Specifically, the endogenous agonist ACh was chosen as this represents the physiologically relevant $\mathrm{mAChR}$ neurotransmitter against which all putative allosteric ligands need to be tested. Oxotremorine-M (Oxo-M) was chosen, as this is commonly used as a high efficacy mAChR agonist in numerous in vitro and in vivo studies (e.g., Valant et al., 2012). Iperoxo (Ixo) was chosen as it remains the highest efficacy mAChR agonist identified to date (Langmead and Christopoulos, 2013; Schrage et al., 2013), and xanomeline (Xan) was chosen because it is a partial agonist, has a functional preference for $M_{1}$ and $M_{4}$ mAChRs over other $\mathrm{mAChR}$ subtypes, and has progressed into clinical trials on the basis of this selectivity (see Introduction).

Initially, the affinities and intrinsic efficacies of the orthosteric agonists were characterized using an assay of $\mathrm{M}_{1}$ mAChR-mediated $\mathrm{IP}_{1}$ accumulation, a classic signaling pathway downstream of activation of $\mathrm{G}_{\mathrm{q} / 11}$-linked receptors. All orthosteric agonists increased $\mathrm{IP}_{1}$ accumulation in our FlpInCHO-hM $\mathrm{h}_{1}$ cell line in a concentration-dependent manner. ACh, Ixo, and Oxo-M were all full agonists in this assay, whereas Xan was a weak partial agonist (with an $E_{\text {max }} \sim 30 \%$ of that observed for ACh; Table 1$)$. The functional affinities $\left(\mathrm{p} K_{\mathrm{A}}\right)$ and operational efficacies $(\tau)$ of the orthosteric probes were also determined at the $M_{1}$ mAChR by treating the cells with the irreversible alkylating agent (PBZ) to occlude the orthosteric site (Furchgott, 1966), thus reducing the number of accessible $M_{1}$ binding sites in the FlpInCHO-hM $\mathrm{h}_{1}$ cells. Increasing levels of alkylation of the orthosteric site by PBZ substantially reduced the $E_{\max }$ of all agonists with minimal effects on the potency of ACh, Oxo-M, and Xan (Fig. 2). Small, albeit significant $(p<0.05)$ effects were observed on the potency of Ixo, where a $0.5-1$ log unit shift was observed when there was treatment with the higher concentrations of PBZ ( 1 and $10 \mu \mathrm{M}$, respectively). Overall, this suggests that this system has a low level of receptor reserve for this pathway in our cell line. The family of curves for each agonist was globally fitted to an operational model of agonism (eq. 1), with the efficacy parameter $\tau$ allowed to vary for each curve (since $\tau$ is determined by receptor density), but all other parameters were constrained to be shared. The resulting agonist functional affinity values, determined as equilibrium dissociation constants $\left(K_{\mathrm{A}}\right)$, and the $\tau$ values for the control curve (absence of PBZ) are listed in Table 1, which confirms a rank order of efficacies of Ixo $(\tau=10.7)>$ Oxo-M $(\tau=$ 4.6) $>\operatorname{ACh}(\tau=3.6)>>\operatorname{Xan}(\tau=0.5)$. In addition to the efficacy estimates, the agonist $K_{\mathrm{A}}$ values revealed that Xan and Ixo had significantly higher affinities for the $M_{1}$ mAChR than ACh or Oxo-M $(P<0.05$, Table 1).

BQCA Exhibits Probe Dependence with Different Orthosteric Agonists at the $\mathbf{M}_{1} \mathbf{m A C h R}$. As outlined in the Introduction, the simplest mechanism to explain probe

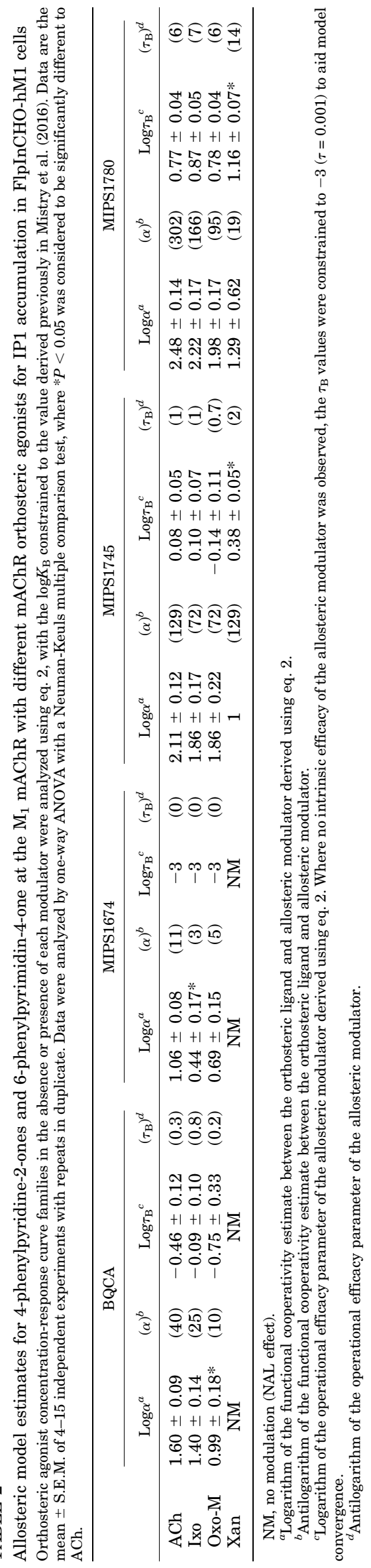


dependence is the classic two-state MWC model. This model predicts that the effect of a PAM is to positively modulate the activity of an orthosteric agonist but negatively modulate the activity of an orthosteric antagonist (inverse agonist) in a manner that tracks with the intrinsic efficacy of the orthosteric ligand, i.e., higher efficacy agonists will be potentiated to a greater degree than lower efficacy agonists; the model does not predict pathway-biased modulation without incorporation of additional receptor states (Canals et al., 2012; Christopoulos, 2014; Ehlert and Griffin, 2014). Thus, the next series of experiments investigated the potential for probe dependence between different agonists and the prototypical $\mathrm{M}_{1}$ mAChR PAM, BQCA.

Figure 3 shows the results of interaction experiments between increasing concentrations of $\mathrm{BQCA}$ and each of the orthosteric agonists $\mathrm{ACh}$, Oxo-M, Ixo, or Xan in the $\mathrm{IP}_{1}$ accumulation assay. BQCA did not affect the $E_{\max }$ of any orthosteric agonist tested but did potentiate the effects of ACh on $\mathrm{IP}_{1}$ signal transduction. The data were globally fitted to an operational model of allostery (eq. 2), where the $\mathrm{p} K_{\mathrm{B}}$ of the allosteric modulator BQCA was constrained to 4.78 (Mistry et al., 2016). This constraint was used to aid model convergence and was selected because it is the binding affinity value determined from full interaction equilibrium binding assays between ACh, BQCA, and $\left\{{ }^{3} \mathrm{H}\right\}$-NMS in the same cell line used for this study (Mistry et al., 2016). The resulting parameter values are listed in Table 2. From these experiments and resulting analysis, two important findings were made. First, the degree of potentiation of each agonist by BQCA was variable ( $\alpha$ values), clearly indicating probe dependence. Second, it was of note that the allosteric modulation was manifested only on the potency of each agonist (i.e., changing the $E C_{50}$ and not on the $E_{\max }$ ). Given that the prior alkylation studies (Fig. 2; Table 1) confirmed that this assay has minimal receptor reserve, any potential allosteric effects on agonist signaling efficacy would have been revealed as increases in the $E_{\max }$, at least for the lower efficacy agonists. The fact that this was not observed in any instance indicates that BQCA modulates only the affinity of the orthosteric agonists, not their efficacy. As such, the co-operativity estimates $(\alpha \beta)$ from the operational model analysis are measures of "pure" affinity modulation $(\alpha)$.

As summarized in Fig. 3 and Table 2, BQCA potentiated ACh $\left(\alpha_{\mathrm{ACh}}=40\right)$ and Ixo $\left(\alpha_{\mathrm{Ixo}}=25\right)$ to the greatest extent; Oxo-M $\left(\alpha_{\text {OxoM }}=10\right)$ was potentiated to a lesser extent, although realistically these differences in potentiation were marginal, showing only a 4 -fold difference at most. BQCA showed no modulation, i.e., was a neutral allosteric ligand (NAL), with respect to the weakest agonist, Xan. On its own, BQCA showed very little to no intrinsic efficacy $\left(\tau_{\mathrm{B}}=0.2-0.8\right)$, confirming previous findings (Yeatman et al., 2014).

Effects of Novel $M_{1}$ mAChR PAMs on ACh-Mediated IP $_{1}$ Accumulation. We next investigated the effects of each of the two 4-phenylpyridine-2-one-based (MIPS1674 and MIPS1745) and the 6-phenylpyrimidin-4-one-based (MIPS1780) analogs on $\mathrm{IP}_{1}$ accumulation mediated by the endogenous agonist ACh (Fig. 4). As observed with BQCA, each of the novel $\mathrm{M}_{1} \mathrm{mAChR}$ PAMs enhanced only the potency of ACh. As above, the allosteric modulator affinity values were constrained to the binding affinity values $\left(\mathrm{p} K_{\mathrm{B}}\right)$ for MIPS1674 (4.45), MIPS1745 (4.50), and MIPS1780 (4.88) that were previously determined by Mistry et al. (2016) in full binding interaction studies in the same cell line as used in this study.
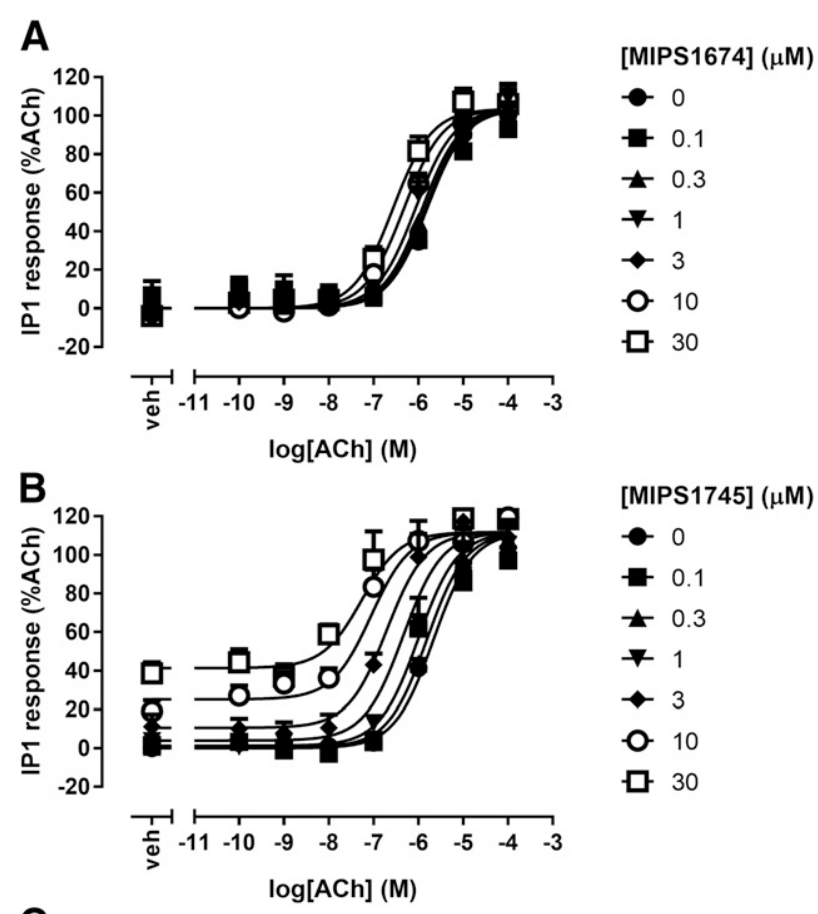

[MIPS1745] $(\mu \mathrm{M})$

C

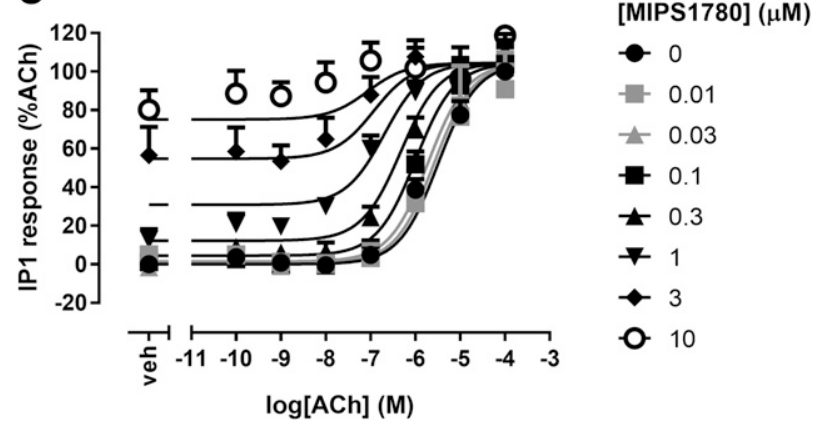

The resulting co-operativity estimates $\left(\alpha_{\mathrm{ACh}}\right)$ are shown in Fig. 6 and Table 2 . The ACh response was potentiated to a greater extent by MIPS1780 $\left(\alpha_{\mathrm{ACh}}=302\right)$ and $\operatorname{MIPS} 1745\left(\alpha_{\mathrm{ACh}}=129\right)$ than BQCA $\left(\alpha_{\mathrm{ACh}}=40\right)$, whereas MIPS1674 $\left(\alpha_{\mathrm{ACh}}=11\right)$ clearly showed a substantially lower degree of potentiation. Interestingly, we also noted a number of differences in the behavior of the novel PAMs compared with our initial preliminary characterization (Mistry et al., 2016). For instance, MIPS1674 showed modest modulatory effects on ACh but little to no direct allosteric agonism. MIPS1745 was not a "pure" PAM as originally described by Mistry et al. (2016) but rather, a PAM-agonist $\left(\tau_{\mathrm{B}}=1.2\right)$ like MIPS1780 $\left(\tau_{\mathrm{B}}=5.9\right)$. Although the same cellular background was used for both the current study and that of Mistry et al. (2016), the $\mathrm{IP}_{1}$ accumulation assay protocol was performed under different conditions (adherent vs. suspended cells), which may account for the differences observed. 
A
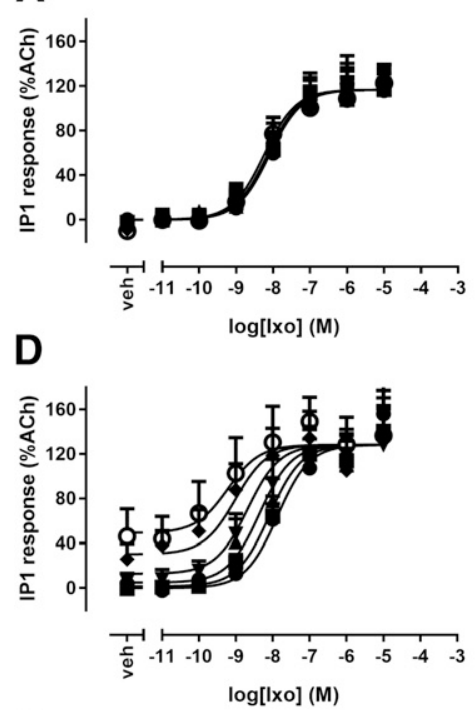

G

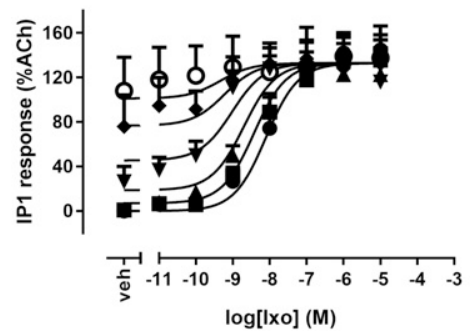

B

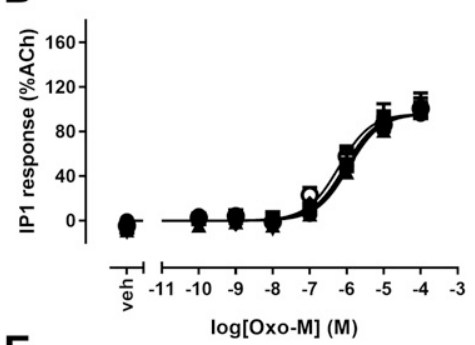

E

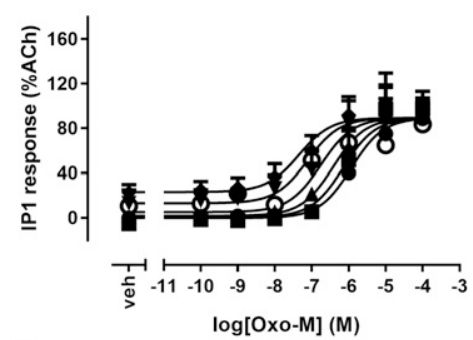

H

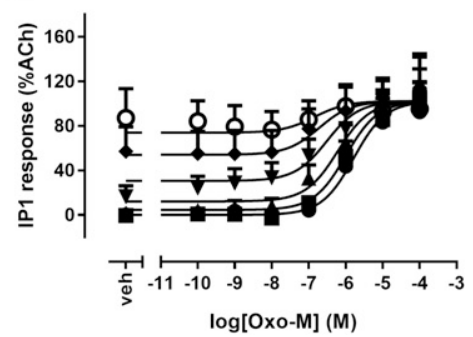

C

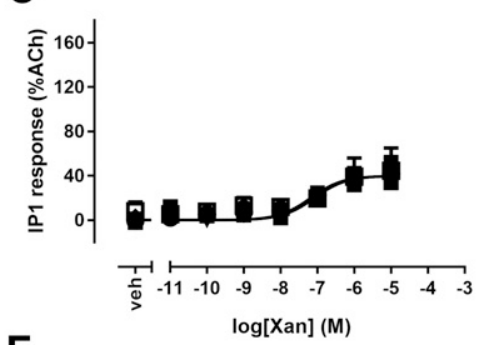

F

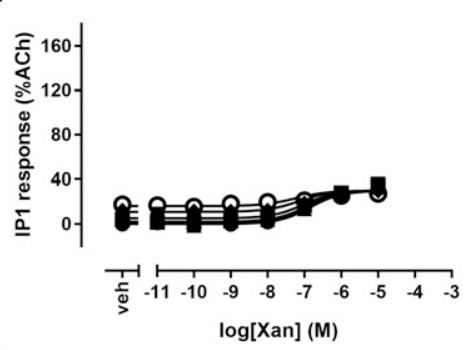

|

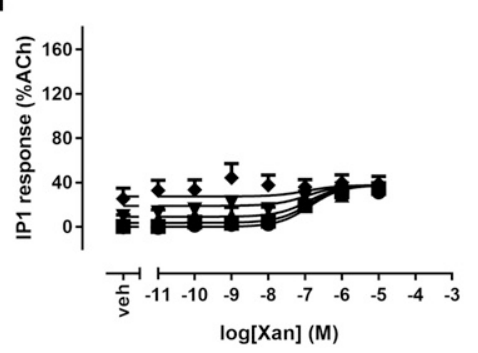

[MIPS1674] $(\mu \mathrm{M})$

- 0

다 0.1

$\pm 0.3$

$\rightarrow 1$

$\bullet 3$

- 10

마 30

[MIPS1745] $(\mu \mathrm{M})$

- 0

다 0.3

$\pm 1$

$\rightarrow 3$

$\uparrow 10$

- 30

[MIPS1780] $(\mu \mathrm{M})$

- 0

다 0.1

$\pm 0.3$

$\boldsymbol{+} 1$

$\leftarrow 3$

- 10

Fig. 5. The novel $\mathrm{M}_{1} \mathrm{PAMs}$ modulate $\mathrm{IP}_{1}$ accumulation with different orthosteric probes to different extents. $\mathrm{IP}_{1}$ accumulation assays in FlpInCHO-hM cells were performed with increasing concentrations of different orthosteric probes $(\mathrm{A}, \mathrm{D}$, and $\mathrm{G}) \mathrm{Ixo},(\mathrm{B}, \mathrm{E}$, and $\mathrm{H}) \mathrm{Oxo}-\mathrm{M}$, or $\left(\mathrm{C}, \mathrm{F}\right.$, and I) Xan at $37^{\circ} \mathrm{C}$ for 1 hour. Allosteric modulators (A-C) MIPS1674, (D-F) MIPS1745, and (G-I) MIPS1780 were co-added with the orthosteric ligands for 1 hour at $37^{\circ} \mathrm{C}$. Curves represent the best global fit to the allosteric operational model (eq. 2) with the resulting parameters found in Table 2. Data are mean \pm S.E.M. of six independent experiments with repeats in duplicate.

Investigation of Mechanisms of Probe Dependence Mediated by MIPS1674, MIPS1780, and MIPS1745 with Different Agonists at the $\mathbf{M}_{1}$ mAChR. To determine whether the novel PAMs exhibit probe dependence, the interaction experiments were extended to include the effects of other mAChR agonists on $\mathrm{IP}_{1}$ accumulation. As observed with BQCA, no effect of the novel PAMs on the maximal response of the various agonists used in this study was detected (Fig. 5), again suggesting that any allosteric modulation by the novel $\mathrm{M}_{1} \mathrm{mAChR}$ PAMs is manifested at the level of agonist binding affinity only. Subsequent analysis of these data by an operational model of allostery (eq. 2) provided co-operativity estimates for individual modulators with each agonist (Table 2; summarized Fig. 6, B-D). MIPS1674 potentiated the ACh response $(\alpha=11)$ to a greater extent than Oxo-M $(\alpha=5)$ and significantly more than that seen with Ixo $(\alpha=3)$, suggesting that this modulator exhibits probe dependence, modulating the endogenous agonist ACh to a greater extent than the higher potency agonist Ixo. MIPS1745 and MIPS1780 behaved like BQCA, in that they potentiated ACh, Ixo, and Oxo-M to similar extents (Fig. 6). Xan was weakly modulated $(\alpha=19)$ by the most robust PAM, MIPS1780, although the co-operativity estimate was associated with a larger error than for the other agonists. No modulation of the Xan response was observed with any of the other allosteric modulators tested, again consistent with a NAL effect. Nonetheless, the overall findings are broadly consistent with those seen with BQCA, that is, the higher efficacy agonists were modulated to a greater extent than the lowest efficacy agonist (Xan). For a weak PAM, i.e., MIPS1674, the overall degree of positive modulation was low irrespective of the agonist (Fig. 6B), whereas for the most robust PAMs, i.e., MIPS1780 and MIPS1745, the magnitude of the positive co-operativity noted with ACh, Oxo-M, or Ixo (Fig. 6) was in the range observed with the prototypical PAM, BQCA.

Novel $M_{1}$ PAMs Show Minimal Evidence of Biased Modulation. It is not uncommon to see different overall degrees of functional PAM effects of GPCR modulators in cellbased assays. Although this may be taken as presumptive evidence of "pathway biased modulation," a simpler explanation is that assays characterized by stronger stimulusresponse coupling (e.g., more amplified responses) may be more prone to manifesting stronger PAM effects owing to the potentially greater sensitivity of PAM-agonism being unmasked in such assays (Keov et al., 2011). It is only when this property is not a contributor that true pathway bias can be considered. Previously, BQCA showed no bias, relative to $\mathrm{ACh}$, when tested against carbachol in a range of signaling assays (Canals et al., 2012; Yeatman et al., 2014). To confirm this general effect we used the endogenous agonist $\mathrm{ACh}$ and 
A

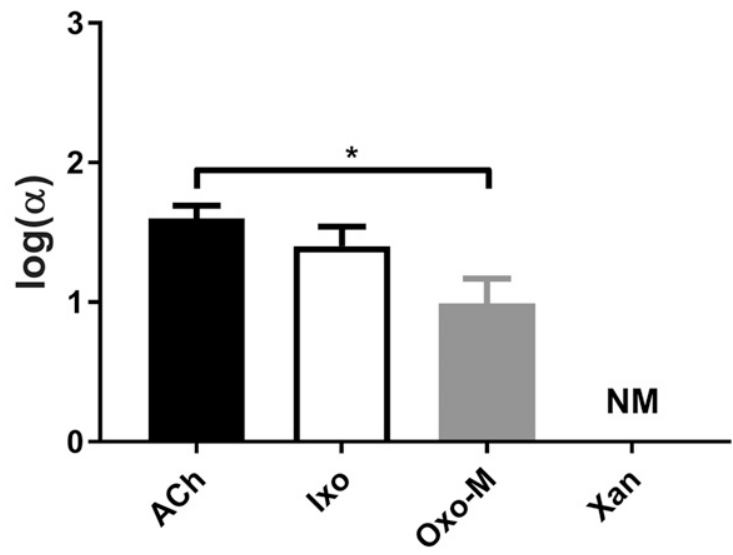

MIPS1745

C

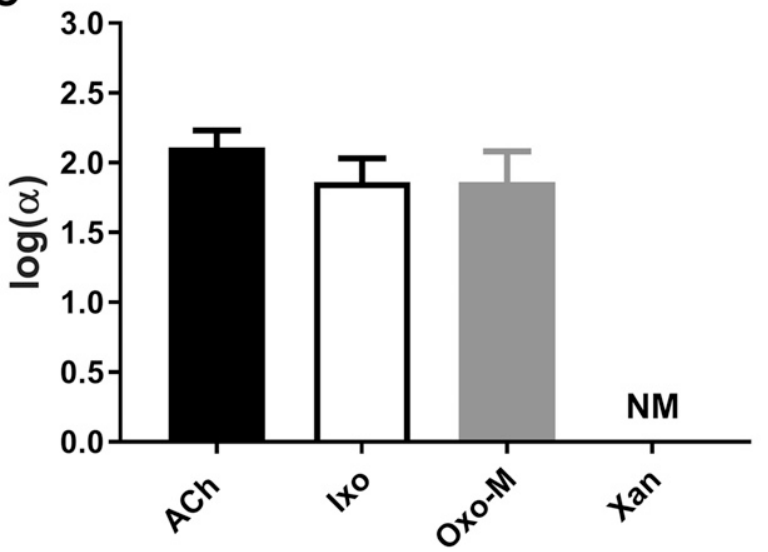

B

MIPS1674

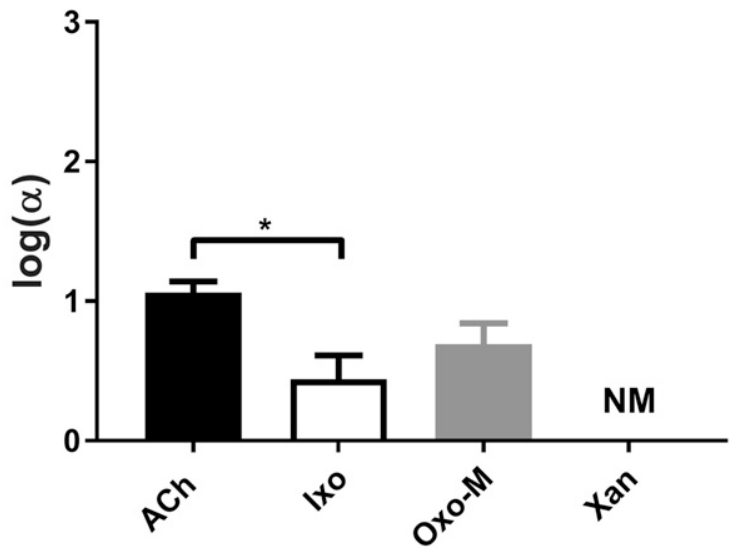

MIPS1780

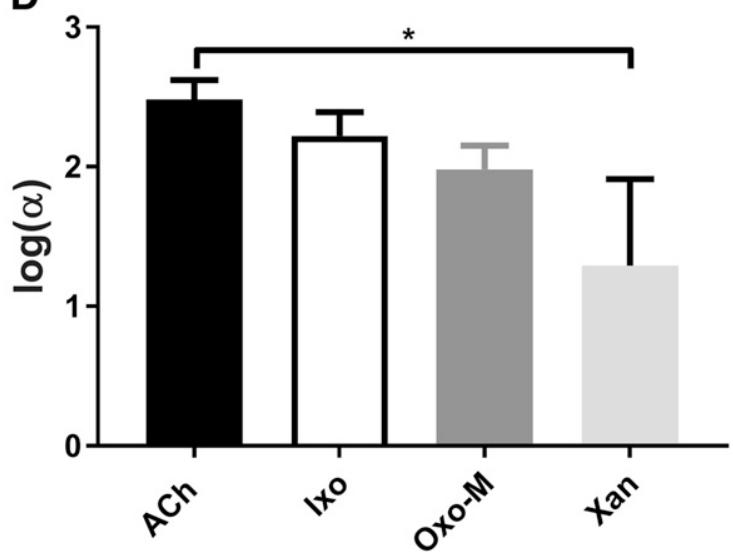

Fig. 6. Probe-dependence between orthosteric agonists and allosteric modulators. Co-operativity estimates (log $\alpha$ ) were derived from global analysis of data sets in Figs. 4 and 5 and resulting parameters are reported in Table 2. (A) BQCA potentiated ACh and Ixo more than Oxo-M. (B) MIPS1674 potentiated ACh to a greater extent than Ixo or Oxo-M. (C) MIPS1745 potentiated ACh, Ixo, and Oxo-M to similar extents. (D) MIPS1780 potentiated ACh, Ixo, and Oxo-M to a greater extent than Xan. Data are mean \pm S.E.M. of 6-15 independent experiments with repeats in duplicate. Data were analyzed by one-way ANOVA with a Neuman-Keuls multiple comparison test, where $* P<0.05$ was considered significantly different.

the positive allosteric modulator BQCA as comparators for the effects of the new chemotypes. We first examined the effect of BQCA on the endogenous agonist ACh toward three signaling pathways: ERK1/2 phosphorylation as a representative of an efficiently coupled pathway, and $\mathrm{IP}_{1}$ accumulation and $\beta$-arrestin-2 recruitment ( $\beta$ arr2) as weakly coupled pathways. In Fig. 7, the family of curves were globally fitted to the operational model of allostery (eq. 2), constraining the $\mathrm{p} K_{\mathrm{B}}$ values to the binding affinity values determined by Mistry et al. (2016), as described above, and with the resulting parameters shown in Table 3. The rank order of co-operativity for the pathways was ERK1/2 $(\alpha=871)>>$ $\operatorname{IP}_{1}(\alpha=40) \geq \beta \operatorname{arr} 2(\alpha=23)$.

The novel 4-phenylpyridine-2-ones and 6-phenylpyrimidin4-one were also tested on the same three pathways, and the data sets were analyzed in the same manner as BQCA (described above). MIPS1745 and MIPS1780 had the greatest efficacy $\left(\tau_{\mathrm{B}}\right)$ toward the more amplified ERK1/2 pathway and lower efficacy toward the $\mathrm{IP}_{1}$ and $\beta$ arr2 pathways (Fig. 8, H-I; Fig. 9). MIPS1780 strongly potentiated $\left(\alpha_{\mathrm{ERK}}=550\right.$, $\alpha_{\mathrm{IP} 1}=309, \alpha_{\beta \operatorname{arr} 2}=229$ ) all pathways. A similar pattern of potentiation was seen with MIPS1745 $\left(\alpha_{\mathrm{ERK}}=380, \alpha_{\mathrm{IP} 1}=\right.$ $\left.129, \alpha_{\beta \text { arr2 }}=42\right)($ Figs. 8 and 9; Table 3$)$. The rank order of co-operativity was ERK1/2 $>\mathrm{IP}_{1}>\beta$ arr 2 ; thus, as observed with BQCA, MIPS1745 and MIPS1780 were PAMs toward all pathways, and the potentiation of the responses tracked with stimulus coupling.

When the MIPS1674 data were analyzed using the operational model of allostery (eq. 2), it did not appear to modulate $\beta$ arr2 recruitment but did weakly modulate the other signaling pathways. As shown in Figs. 8 and 9 and Table 3, MIPS1674 had weak efficacy toward the ERK1/2 $\left(\tau_{\mathrm{B}}=1.4\right)$ pathway and no efficacy for the $\mathrm{IP}_{1}$ or $\beta$ arr2 pathways. MIPS1674 weakly modulated ACh activity toward ERK1/2 and $\mathrm{IP}_{1}$, with a rank order of co-operativity of $\operatorname{IP}_{1}(\alpha=12)>$ ERK1/2 $(\alpha=4)$. By visual inspection of the concentration response curves, MIPS1674 acted as a "pure" PAM toward IP 1 , is an allosteric agonist with minimal PAM activity toward ERK1/2, and was an NAL toward $\beta$ arr2. Although these results may suggest that MIPS1674 has the potential to be a biased modulator at the $\mathrm{M}_{1} \mathrm{mAChR}$, a more parsimonious explanation is that the low level of receptor expression and 
A

B

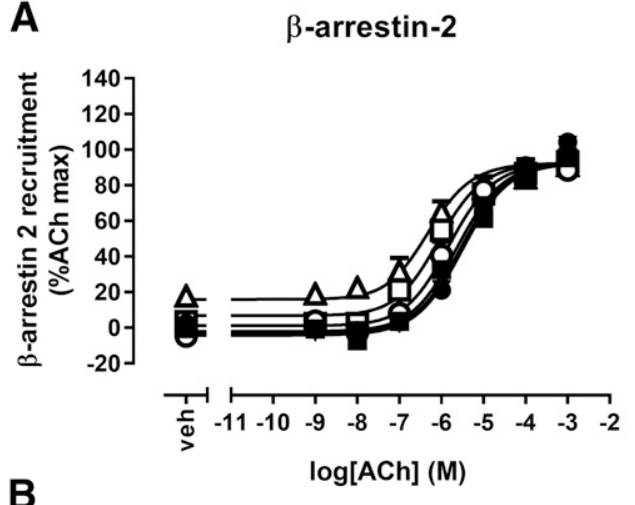

IP1 accumulation

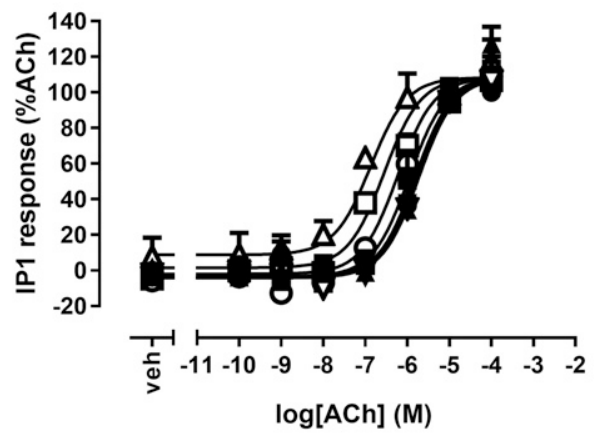

C

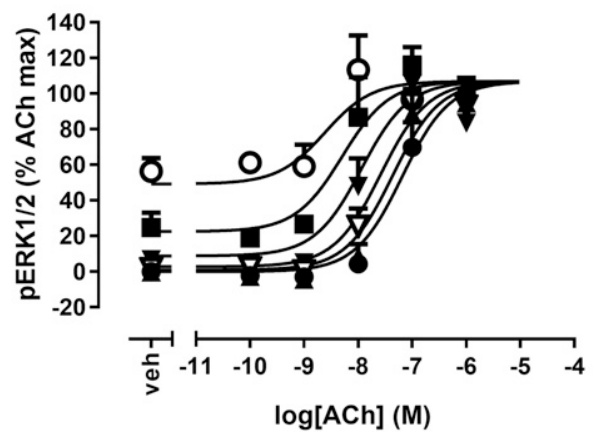

[BQCA] $(\mu \mathrm{M})$

$-0$

$\pm 0.01$

$\boldsymbol{\nabla} 0.03$

$\rightarrow 0.1$

$+0.3$

- 1

마 3

$\Delta 10$

Fig. 7. BQCA potentiates $\mathrm{ACh}$ at three distinct signaling pathways. FlpInCHO-hM $\mathrm{h}_{1}$ cells were stimulated with different concentrations of $\mathrm{ACh}$ and responses to three different signaling pathways were measured. $\beta$-arrestin 2 recruitment and ERK1/2 responses were measured after 5 minutes of stimulation, whereas $\mathrm{IP}_{1}$ accumulation was measured after 1 hour. BQCA potentiates ACh signaling toward (A) $\beta$-arrestin 2 recruitment, (B) $\mathrm{IP}_{1}$ accumulation, and (C) ERK1/2 phosphorylation. Data were fitted to the allosteric operational model with the resulting parameters reported in Table 3. Data are mean \pm S.E.M. of 6-15 independent experiments with repeats in duplicate.

differences in stimulus-response coupling the $\mathrm{IP}_{1}$ and $\beta$-arrestin recruitment pathway resulted in an insufficient response window to reveal any potentiation of the ACh $\beta$-arrestin recruitment response, particularly since MIPS1674 was the least effective PAM of the new series.

\section{Discussion}

The discovery of BQCA ushered in a new era of drug discovery for the $\mathrm{M}_{1} \mathrm{mAChR}$, particularly with regard to novel potential modalities for treatment of cognitive deficits (Ma et al., 2009; Davie et al., 2013). Subsequent detailed

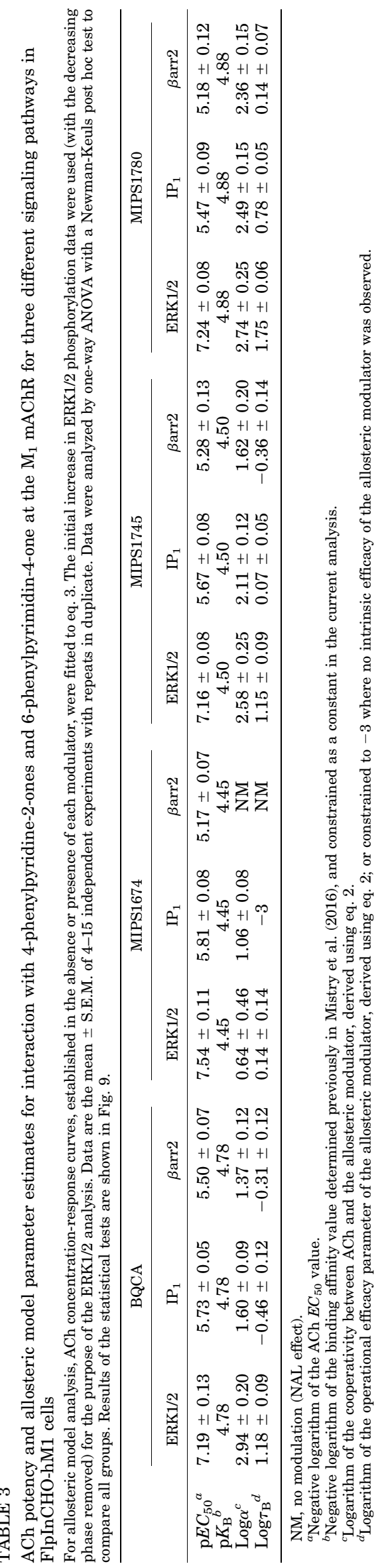



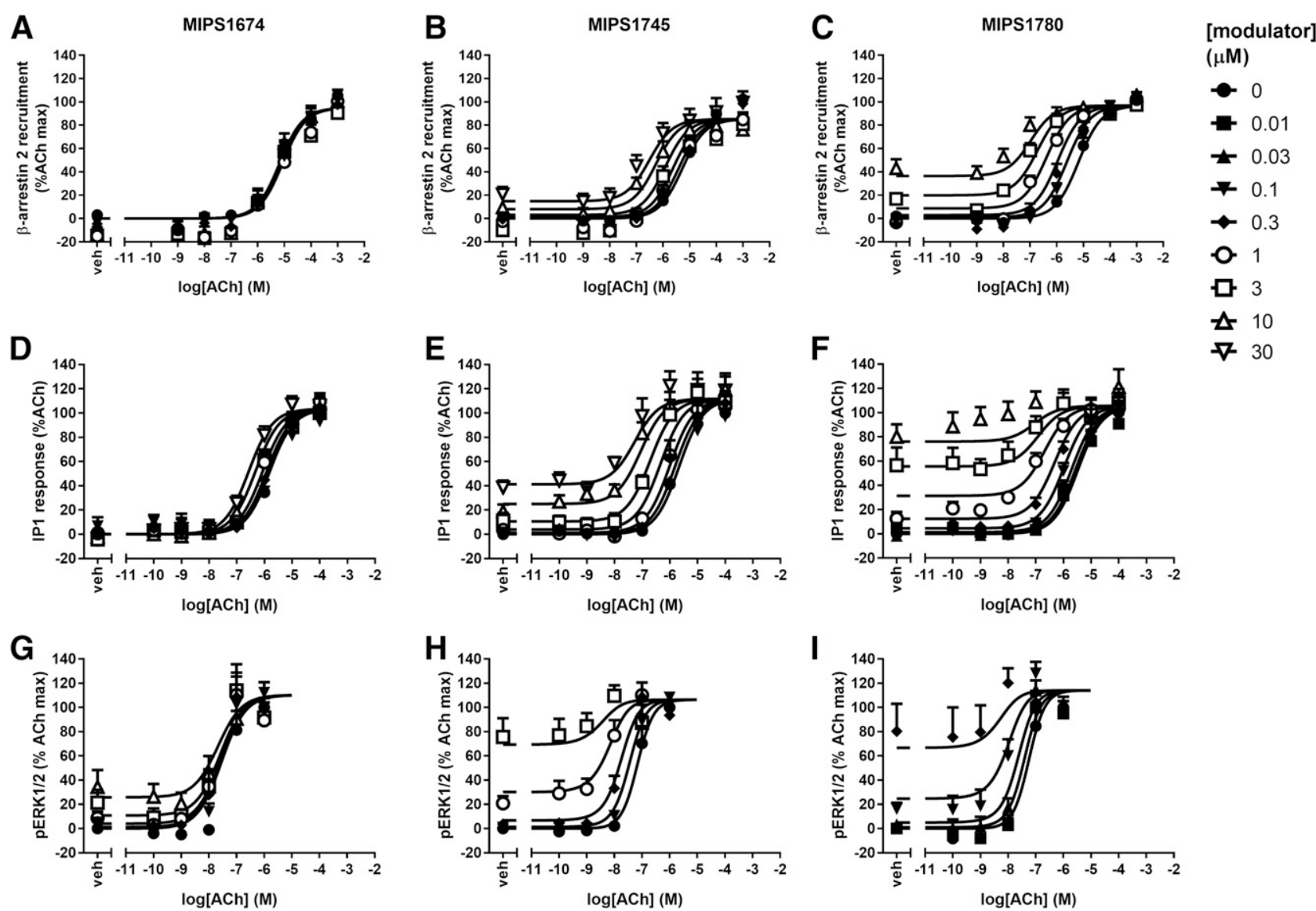

Fig. 8. Minimal evidence for pathway-biased modulation by the novel $\mathrm{M}_{1}$ PAM scaffolds. FlpInCHO-hM $\mathrm{M}_{1}$ cells were stimulated with different concentrations of $\mathrm{ACh}$ and responses to three different signaling pathways were measured. $\beta$-arrestin 2 recruitment and pERK1/2 responses were measured after 5 minutes of stimulation and $\mathrm{IP}_{1}$ accumulation was measured after 1 hour. MIPS1674 acted as a neutral allosteric ligand toward (A) $\beta$-arrestin 2 recruitment, as a "pure" PAM for (D) $\mathrm{IP}_{1}$ accumulation and an allosteric agonist with minimal PAM activity toward (G) ERK1/2 signaling. MIPS1745 and MIPS1780 were PAM-agonists toward (B and C) $\beta$-arrestin 2 recruitment, (E and F) $\mathrm{IP}_{1}$ accumulation, and (H and I) ERK1/2 phosphorylation, suggesting that they are not biased modulators of ACh at the $\mathrm{M}_{1} \mathrm{mAChR}$. Fitted curves are from global analysis of datasets according to an operational model of allosterism (eq. 2), with parameter estimates shown in Table 3. Data are mean \pm S.E.M. of 4-15 independent experiments with repeats in duplicate.

pharmacological characterization of BQCA also revealed key features consistent with the simplest mechanism of receptor allostery, namely the two-state MWC model (Canals et al., 2012), and thus provided a guide for the subsequent pharmacological assessment of novel allosteric modulators at both mAChRs and other GPCRs. This is relevant to the current study, which investigated novel PAMs chemically distinct from BQCA. Preliminary findings with the 4-phenylpyridine2-ones and 6-phenyl-4-one suggested that they may have diverse pharmacological phenotypes, reflective of more complex, and potentially biased, allosteric behaviors (Mistry et al., 2016). The main findings of this study indicate that the novel $M_{1}$ mAChR PAMs display probe dependence at the $M_{1}$ $\mathrm{mAChR}$ but minimal evidence of biased modulation. These findings have implications for future elaboration of this new chemical series, with an ultimate aim toward producing molecules that are more tractable to "drug-like" behavior than BQCA.

As indicated previously, the key prediction of a two-state MWC model is that the degree of allosteric modulation will "track" with the efficacy of the orthosteric probe, i.e., if an allosteric ligand prefers an active receptor state, it follows that: 1) It will be a PAM of agonists and a NAM (negative allosteric modulator) of inverse agonists (and vice versa for modulators that prefer the inactive state), 2) that higher efficacy agonists will be potentiated by PAMs to a greater extent than lower efficacy agonists, and 3), there should be no pathway-biased modulation (Canals et al., 2011, 2012). Any divergence from this behavior could suggest a more complex mode of action involving multiple receptor states. However, since cellular stimulus-response coupling will have an effect on observed agonism (Keov et al., 2011), it is vital to account for this property and, where possible, apply approaches that divorce the host system-dependence of allostery and agonism from the underlying molecular parameters that govern these phenomena. The different degree of maximal agonist responsiveness observed in the $\mathrm{IP}_{1}$ accumulation assays indicated that our recombinant cell line probably exhibited a very low receptor reserve, which was confirmed by receptor alkylation experiments and application of an operational model of agonism. However, it should be noted that a detailed analysis of the predictions of the MWC model in operational terms by Ehlert and Griffin (2014) found that the only aspects of the stimulus-response transduction mechanism that should affect observed modulation ( $\alpha \beta$ values) are receptor-proximal events, e.g., receptor or transducer stoichiometry. Moreover, 


\section{Efficacy}

A

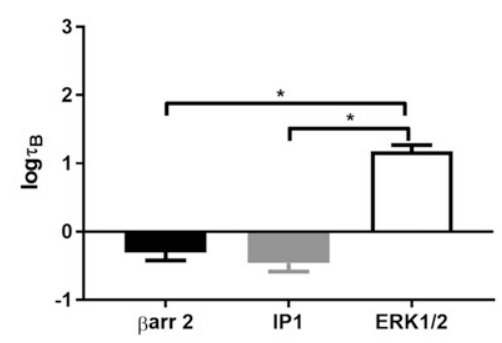

C

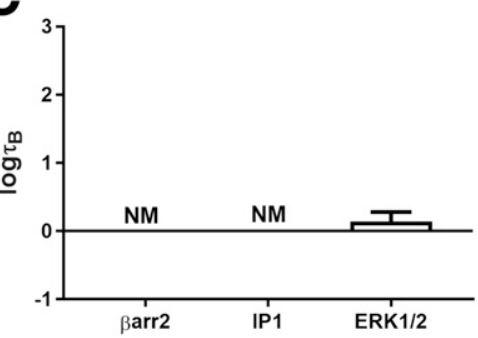

E
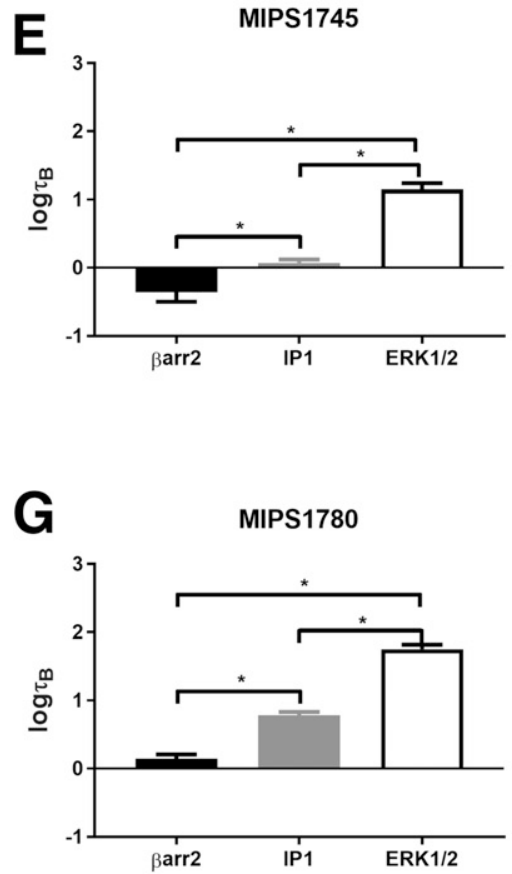

\section{Co-operativity}

B

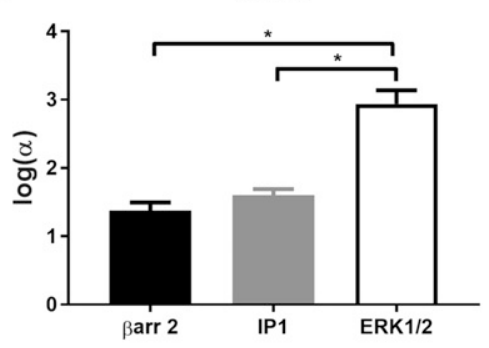

D

MIPS1674

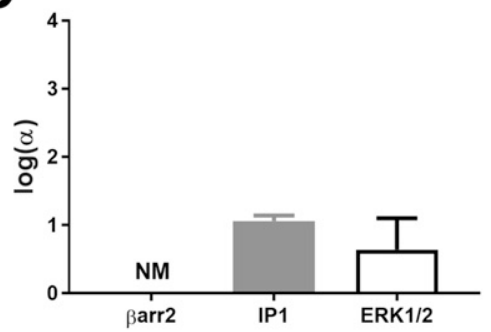

$\mathbf{F}$

MIPS1745

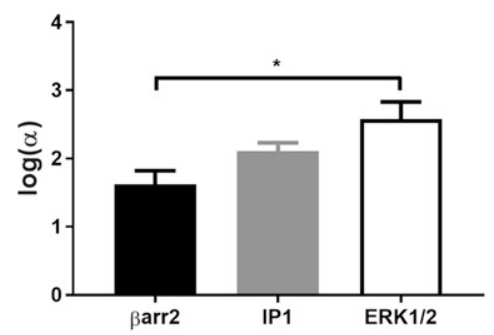

H MIPS1780

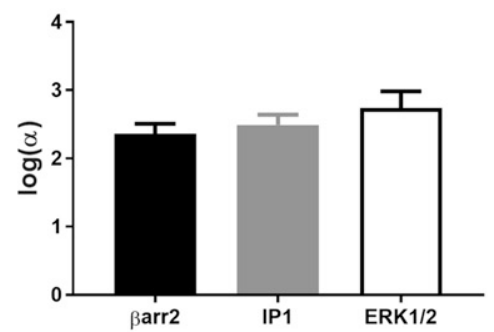

Fig. 9. Comparison of the efficacy and co-operativity estimates of the 4-phenylpyridine-2-one and 6-phenylpyrimidin-4-one PAMs toward three signaling pathways. FlpInCHO-hM I $_{1}$ cells were stimulated with different concentrations of $\mathrm{ACh}$ and responses to three different signaling pathways were measured. ERK1/2 phosphorylation and $\beta$-arrestin 2 recruitment were measured after 5 -minute stimulation at $37^{\circ} \mathrm{C}$. $\mathrm{IP}_{1}$ accumulation was measured following stimulation with ligands for 1 hour at $37^{\circ} \mathrm{C}$. Data from interaction experiments between different concentrations of ACh and PAMs were fitted to the operational model of allosterism (eq. 2) and the (A, C, E, and G) efficacy (log $\left.\tau_{\mathrm{B}}\right)$ and $(\mathrm{B}, \mathrm{D}, \mathrm{F}$, and $\mathrm{H})$ cooperativity $(\log \alpha)$ parameters were obtained (also shown in Table 3 ). Data are mean \pm S.E.M. of four to eight independent experiments with repeats in duplicate. Data were analyzed by one-way ANOVA, with Neuman-Keuls multiple comparisons tests, where $* P<0.05$ was considered to be significantly different. low efficacy agonists may be expected to show changes in the maximal response (Ehlert and Griffin, 2014), which was not observed in our current study (e.g., with Xan). It is possible that this reflects a divergence from an MWC mechanism or, more parsimoniously, that Xan selects for a very low activity state such that any effects on its signaling efficacy simply cannot be observed over the concentration range of PAMs used in our study.

The low receptor reserve of the FlpInCHO-hM $\mathrm{h}_{1}$ cell system proved both advantageous and, to some extent, disadvantageous depending on the question that was asked. An advantage of the low receptor reserve system is that the lack of effect of BQCA and the novel PAMs on agonist $E_{\max }$, although modulating potency, could only be explained if the modulators mediated their effects purely through changing agonist affinity, as efficacy effects would manifest as a change in $E_{\text {max }}$, particularly for Xan. This allowed the application of a simplified operational model of allostery that quantified the global cooperativity of the PAMs (Aurelio et al., 2009). Although differences were observed in the behaviors and operational model parameter estimates in our $\mathrm{IP}_{1}$ 
accumulation studies versus those performed by Mistry et al. (2016), this probably reflected variances in $\mathrm{IP}_{1}$ assay protocol, as well as potential variability in cell background owing to cell passage. Irrespective, our analysis suggested that all novel PAMs, like BQCA, tended to potentiate higher efficacy agonists to a greater extent than the low efficacy agonist, Xan.

A possible disadvantage of the low receptor reserve displayed by our cell line was evident in the studies of allosteric modulation between different pathways linked to $\mathrm{M}_{1} \mathrm{mAChR}$ activation. Ideally, the choice of pathways was designed to reflect events that are generally considered substantially proximal (e.g., $\beta$-arrestin 2 recruitment) or substantially downstream (e.g., pERK1/2) from receptor activation, with $\mathrm{IP}_{1}$ accumulation representing a pathway that would display a degree of stimulus-response coupling somewhere between the two (Lanzafame et al., 2003; Canals et al., 2012; Abdul-Ridha et al., 2014). This, in turn, would allow for a clear delineation of whether the modulation between a given agonist-modulator pair tracked with the degree of stimulus-response coupling or differed. The former scenario was generally the case when comparing the effects of the PAMs on ACh-mediated pERK1/2 to either $\beta$-arrestin 2 recruitment or $\mathrm{IP}_{1}$ accumulation, but more equivocal when comparing ACh-mediated $\beta$-arrestin 2 recruitment to $\mathrm{IP}_{1}$ accumulation. However, if the degree of receptor coupling efficiency to the $\mathrm{IP}_{1}$ pathway and $\beta$-arrestin 2 recruitment pathways was similar, owing to low receptor reserve, then the MWC model would predict similar degrees of potentiation at each pathway, and it is thus not surprising that the PAM effects on $\mathrm{ACh}$ at $\beta$-arrestin 2 recruitment or $\mathrm{IP}_{1}$ accumulation did not display the degree of separation seen when compared with the pERK1/2 assays.

It is now established that allosteric ligands have the potential to engender multiple biologically active GPCR states (Wisler et al., 2007; Davey et al., 2012; Kenakin et al., 2012). As a consequence, deviations from simple MWC-governed allosteric behavior in terms of probe dependence and pathway bias have been observed at multiple GPCRs, emphasizing the importance of routinely investigating these therapeutically relevant paradigms whenever characterizing novel ligands (Price et al., 2005; Valant et al., 2012; Christopoulos, 2014). For example, at the $\mathrm{M}_{2} \mathrm{mAChR}$, the allosteric modulator LY2033298 positively modulates the binding affinity of multiple orthosteric agonists but has either positive or negative allosteric effects on the signaling efficacy and signaling pathway of the same agonists. Thus, functionally, LY2033298 is a PAM of Oxo-M, an NAL of ACh, and an NAM of Xan (Valant et al., 2012). This type of probe dependence cannot be reconciled within a two-state mechanism and is clearly suggestive of biased modulation involving multiple receptor active states (Christopoulos, 2014). Given that surrogate orthosteric probes are often used preclinically in vitro or in vivo, owing to the metabolic instability of the endogenous GPCR agonist (Leach et al., 2010), or that multiple endogenous ligands and their metabolites exist for a single GPCR (Wootten et al., 2012; van der Westhuizen et al., 2015), a lack of appreciation of the differences underlying probe dependence as a function of intrinsic efficacy (i.e., simple two-state MWC model) or probe dependence as a function of different conformational states (i.e., biased modulation), can lead to misinterpretation of preclinical data and thus inappropriate selection of potential allosteric drug candidates for further optimization and development.
In conclusion, despite possessing a chemically distinct scaffold, the similar molecular fingerprints of the 4-phenylpyridine-2-one and 6-phenylpyrimidin-4-one PAMs to that of BQCA suggests a similar molecular mechanism of action, and is consistent with a common binding site. This site is proposed to overlap with the "common" allosteric binding pocket located in the extracellular vestibule of mAChRs. However, additional structure-function analyses are required to confirm this hypothesis. Perhaps more importantly, the availability of a novel chemical scaffold of known molecular properties could facilitate the development of superior $M_{1}$ mAChR PAMs with a higher probability of clinical translation than first-generation compounds exemplified by BQCA.

\section{Acknowledgments}

The authors thank Dr. Christian Felder, Eli Lilly, for the generous gift of xanomeline.

\section{Authorship Contributions}

Participated in research design: van der Westhuizen, Spathis, Valant, Christopoulos.

Conducted experiments: van der Westhuizen, Spathis, Valant, Khajehali.

Contributed new reagents or analytic tools: Jörg, Mistry, Scammells.

Performed data analysis: van der Westhuizen, Spathis, Valant, Christopoulos.

Wrote or contributed to the writing of the manuscript: van der Westhuizen, Spathis, Khajehali, Jörg, Mistry, Capuano, Tobin, Sexton, Scammells, Valant, Christopoulos.

\section{References}

Abdul-Ridha A, Lane JR, Mistry SN, López L, Sexton PM, Scammells PJ, Christopoulos A, and Canals M (2014) Mechanistic insights into allosteric structurefunction relationships at the M1 muscarinic acetylcholine receptor. $J$ Biol Chem 289:33701-33711.

Aurelio L, Valant C, Flynn BL, Sexton PM, Christopoulos A, and Scammells PJ (2009) Allosteric modulators of the adenosine A1 receptor: synthesis and pharmacological evaluation of 4-substituted 2-amino-3-benzoylthiophenes. J Med Chem 52:4543-4547.

Black JW and Leff P (1983) Operational models of pharmacological agonism. Proc $R$ Soc Lond B Biol Sci 220:141-162.

Bodick NC, Offen WW, Levey AI, Cutler NR, Gauthier SG, Satlin A, Shannon HE, Tollefson GD, Rasmussen K, Bymaster FP, et al. (1997) Effects of xanomeline, a selective muscarinic receptor agonist, on cognitive function and behavioral symptoms in Alzheimer disease. Arch Neurol 54:465-473.

Bymaster FP, McKinzie DL, Felder CC, and Wess J (2003) Use of M1-M5 muscarinic receptor knockout mice as novel tools to delineate the physiological roles of the muscarinic cholinergic system. Neurochem Res 28:437-442.

Canals M, Lane JR, Wen A, Scammells PJ, Sexton PM, and Christopoulos A (2012) A Monod-Wyman-Changeux mechanism can explain G protein-coupled receptor (GPCR) allosteric modulation. J Biol Chem 287:650-659.

Canals M, Sexton PM, and Christopoulos A (2011) Allostery in GPCRs: 'MWC' revisited. Trends Biochem Sci 36:663-672.

Caulfield MP (1993) Muscarinic receptors-characterization, coupling and function. Pharmacol Ther 58:319-379.

Changeux JP and Christopoulos A (2016) Allosteric modulation as a unifying mechanism for receptor function and regulation. Cell 166:1084-1102.

Christopoulos A (1998) Assessing the distribution of parameters in models of ligandreceptor interaction: to log or not to log. Trends Pharmacol Sci 19:351-357.

Christopoulos A (2014) Advances in G protein-coupled receptor allostery: from function to structure. Mol Pharmacol 86:463-478.

Conn PJ, Christopoulos A, and Lindsley CW (2009) Allosteric modulators of GPCRs: a novel approach for the treatment of CNS disorders. Nat Rev Drug Discov 8:41-54

Cortés R, Probst A, and Palacios JM (1987) Quantitative light microscopic autoradiographic localization of cholinergic muscarinic receptors in the human brain: forebrain. Neuroscience 20:65-107.

Cortés R, Probst A, Tobler HJ, and Palacios JM (1986) Muscarinic cholinergic receptor subtypes in the human brain. II. Quantitative autoradiographic studies. Brain Res 362:239-253.

Davey AE, Leach K, Valant C, Conigrave AD, Sexton PM, and Christopoulos A (2012) Positive and negative allosteric modulators promote biased signaling at the calcium-sensing receptor. Endocrinology 153:1232-1241.

Davie BJ, Christopoulos A, and Scammells PJ (2013) Development of M1 mAChR allosteric and bitopic ligands: prospective therapeutics for the treatment of cognitive deficits. ACS Chem Neurosci 4:1026-1048.

Davie BJ, Valant C, White JM, Sexton PM, Capuano B, Christopoulos A and Scammells PJ (2014) Synthesis and pharmacological evaluation of analogues 
of benzyl quinolone carboxylic acid (BQCA) designed to bind irreversibly to an allosteric site of the $\mathrm{M}_{1}$ muscarinic acetylcholine receptor. $J$ Med Chem 57 : $5405-5418$.

Davoren JE, Lee CW, Garnsey M, Brodney MA, Cordes J, Dlugolenski K, Edgerton JR, Harris AR, Helal CJ, Jenkinson S, et al. (2016) Discovery of the potent and selective M1 PAM-agonist $N$-[(3R,4S)-3-hydroxytetrahydro-2H-pyran-4-yl]-5methyl-4-[4-(1,3-thiazol-4-yl)benzyl]pyridine-2-carboxamide (PF-06767832): evaluation of efficacy and cholinergic side effects. J Med Chem 59:6313-6328.

Ehlert FJ and Griffin MT (2014) Estimation of ligand affinity constants for receptor states in functional studies involving the allosteric modulation of $\mathrm{G}$ protein-coupled receptors: implications for ligand bias. J Pharmacol Toxicol Methods 69:253-279.

Ehlert FJ and Tran LP (1990) Regional distribution of M1, M2 and non-M1, non-M2 subtypes of muscarinic binding sites in rat brain. J Pharmacol Exp Ther 255: 1148-1157.

Furchgott RF (1966) The use of b-haloalkylamines in the differentiation of receptors and in the determination of dissociation constants of receptor-agonist complexes. Adv Drug Res 3:21-55.

Kenakin T (2005) New concepts in drug discovery: collateral efficacy and permissive antagonism. Nat Rev Drug Discov 4:919-927.

Kenakin T and Christopoulos A (2013) Signalling bias in new drug discovery: detection, quantification and therapeutic impact. Nat Rev Drug Discov 12:205-216.

Kenakin T, Watson C, Muniz-Medina V, Christopoulos A, and Novick S (2012) A simple method for quantifying functional selectivity and agonist bias. ACS Chem Neurosci 3:193-203.

Keov P, Sexton PM, and Christopoulos A (2011) Allosteric modulation of G protein-coupled receptors: a pharmacological perspective. Neuropharmacology 60:24-35.

Kruse AC, Kobilka BK, Gautam D, Sexton PM, Christopoulos A, and Wess J (2014) Muscarinic acetylcholine receptors: novel opportunities for drug development. Nat Rev Drug Discov 13:549-560.

Kruse AC, Ring AM, Manglik A, Hu J, Hu K, Eitel K, Hübner H, Pardon E, Valant C, Sexton PM, et al. (2013) Activation and allosteric modulation of a muscarinic acetylcholine receptor. Nature 504:101-106.

Langmead CJ and Christopoulos A (2013) Supra-physiological efficacy at GPCRs: superstition or super agonists? Br J Pharmacol 169:353-356.

Langmead CJ, Watson J, and Reavill C (2008) Muscarinic acetylcholine receptors as CNS drug targets. Pharmacol Ther 117:232-243.

Lanzafame AA, Christopoulos A, and Mitchelson F (2003) Cellular signaling mechanisms for muscarinic acetylcholine receptors. Receptors Channels 9:241-260.

Leach K, Loiacono RE, Felder CC, McKinzie DL, Mogg A, Shaw DB, Sexton PM, and Christopoulos A (2010) Molecular mechanisms of action and in vivo validation of an M4 muscarinic acetylcholine receptor allosteric modulator with potential antipsychotic properties. Neuropsychopharmacology 35:855-869.

Ma L, Seager MA, Wittmann M, Jacobson M, Bickel D, Burno M, Jones K, Graufelds $\mathrm{VK}, \mathrm{Xu}$ G, Pearson M, et al. (2009) Selective activation of the M1 muscarinic acetylcholine receptor achieved by allosteric potentiation [published correction appears in Proc Natl Acad Sci U S A (2009) 106:18040]. Proc Natl Acad Sci U S A 106:15950-15955.
Melancon BJ, Tarr JC, Panarese JD, Wood MR, and Lindsley CW (2013) Allosteric modulation of the M1 muscarinic acetylcholine receptor: improving cognition and a potential treatment for schizophrenia and Alzheimer's disease. Drug Discov Today 18:1185-1199.

Mistry SN, Jörg M, Lim H, Vinh NB, Sexton PM, Capuano B, Christopoulos A, Lane JR, and Scammells PJ (2016) 4-phenylpyridin-2-one derivatives: a novel class of positive allosteric modulator of the M1 muscarinic acetylcholine receptor. $J \mathrm{Med}$ Chem 59:388-409.

Monod J, Wyman J, and Changeux JP (1965) On the nature of allosteric transitions: a plausible model. $J$ Mol Biol 12:88-118.

Nathanson NM (2008) Synthesis, trafficking, and localization of muscarinic acetylcholine receptors. Pharmacol Ther 119:33-43.

Price MR, Baillie GL, Thomas A, Stevenson LA, Easson M, Goodwin R, McLean A, McIntosh L, Goodwin G, Walker G, et al. (2005) Allosteric modulation of the cannabinoid CB1 receptor. Mol Pharmacol 68:1484-1495.

Sauerberg P, Olesen PH, Nielsen S, Treppendahl S, Sheardown MJ, Honoré T, Mitch CH, Ward JS, Pike AJ, Bymaster FP, et al. (1992) Novel functional M1 selective muscarinic agonists. Synthesis and structure-activity relationships of $3-(1,2,5$ thiadiazolyl)-1,2,5,6-tetrahydro-1-methylpyridines. J Med Chem 35:2274-2283.

Schrage R, Seemann WK, Klöckner J, Dallanoce C, Racké K, Kostenis E, De Amici M, Holzgrabe U, and Mohr K (2013) Agonists with supraphysiological efficacy at the muscarinic M2 ACh receptor. Br J Pharmacol 169:357-370.

Shekhar A, Potter WZ, Lightfoot J, Lienemann J, Dubé S, Mallinckrodt C, Bymaster FP, McKinzie DL, and Felder CC (2008) Selective muscarinic receptor agonist xanomeline as a novel treatment approach for schizophrenia. Am J Psychiatry 165:1033-1039.

Valant C, Felder CC, Sexton PM, and Christopoulos A (2012) Probe dependence in the allosteric modulation of a G protein-coupled receptor: implications for detection and validation of allosteric ligand effects. Mol Pharmacol 81:41-52.

van der Westhuizen ET, Valant C, Sexton PM, and Christopoulos A (2015) Endogenous allosteric modulators of G protein-coupled receptors. J Pharmacol Exp Ther 353:246-260.

Wess J (2004) Muscarinic acetylcholine receptor knockout mice: novel phenotypes and clinical implications. Annu Rev Pharmacol Toxicol 44:423-450.

Wisler JW, DeWire SM, Whalen EJ, Violin JD, Drake MT, Ahn S, Shenoy SK and Lefkowitz RJ (2007) A unique mechanism of beta-blocker action: carvedilo stimulates beta-arrestin signaling. Proc Natl Acad Sci USA 104:16657-16662.

Wootten D, Savage EE, Valant C, May LT, Sloop KW, Ficorilli J, Showalter AD

Willard FS, Christopoulos A, and Sexton PM (2012) Allosteric modulation of endogenous metabolites as an avenue for drug discovery. Mol Pharmacol 82:281-290.

Yeatman HR, Lane JR, Choy KH, Lambert NA, Sexton PM, Christopoulos A, and Canals M (2014) Allosteric modulation of M1 mu2scarinic acetylcholine receptor internalization and subcellular trafficking. $J$ Biol Chem 289:15856-15866.

Address correspondence to: Dr. Arthur Christopoulos, Drug Discovery Biology, Monash Institute of Pharmaceutical Sciences, 381 Royal Parade, Parkville 3052 VIC, Australia. E-mail: Arthur.Christopoulos@monash.edu 